\title{
Building Technology Project Summaries
}

\section{0-1981}

\section{All100 985551}

NBS

\section{PUBLICATIO}
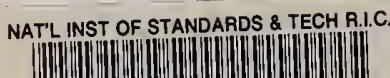

(1)

A11100985551

Unlted States. Natlo/Bullding technology 197

QC100.U57 V446-5;1981 C.2 NBS-PUB-C 197

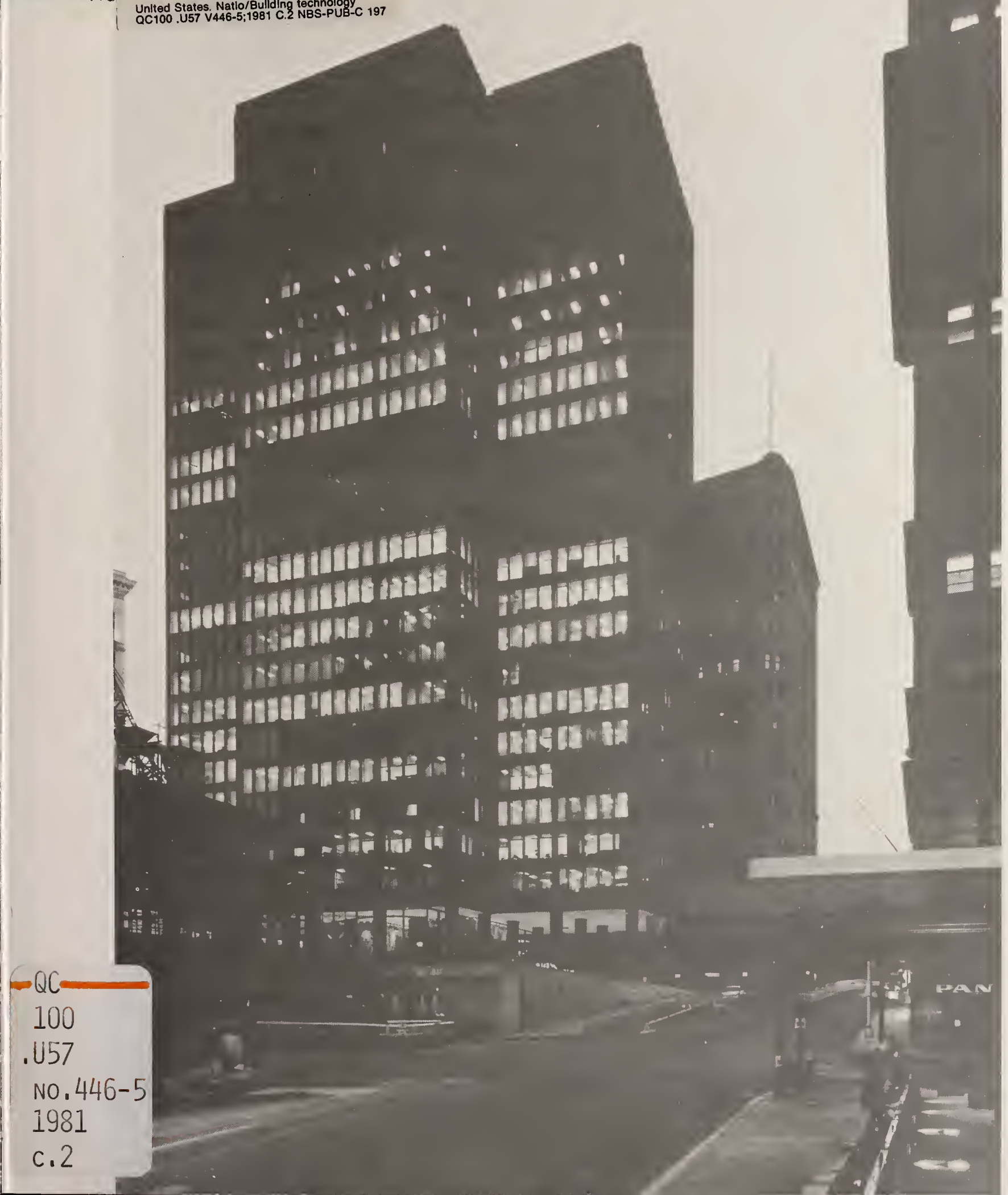


(Cover photograph courtesy of the Department of Housing and Urban Development.) 


\section{Building Technology \\ Project Summaries}

\section{0-1981}

\section{NBS SP 446-5}

Editors:

Noel Raufaste

Michael Olmert

Center for Building Technology

National Engineering Laboratory

National Bureau of Standards

U.S. Department of Commerce

Washington, DC 20234

U.S. DEPARTMENT OF COMMERCE, Malcolm Baldrige, Secretary

NATIONAL BUREAU OF STANDARDS, Ernest Ambler, Director

Issued July 1981 
National Bureau of Standards Special Publication 446-5

Nat. Bur. Stand. (U.S.), Spec. Publ. 446-5, 82 pages (July 1981)

CODEN: XNBSAV

For sale by the Superintendent of Documents, U.S. Government Printing Office, Washington, D C 20402 Price $\$ 4.50$

(Add 25 percent for other than U.S. mailing ) 
The mission of the Center for Building Technology (CBT) is to increase the usefulness, safety, and economy of buildings through the advancement of building technology and its application to the improvement of building practice. CBT's research activities support the building technology programs of Federal, State, and local governments; assist the design professions, building officials, and the research community by developing improved design criteria; and assist manufacturers of building products by developing methods for evaluating innovative materials, components, and systems.

CBT's programs address construction productivity, building safety, and energy conservation. Typical CBT activities include: investigating failures, such as the Willow Island cooling tower accident, to determine needs for improved design and construction practices; improving measurement techniques, such as development of accurate equipment to measure the performance of thick insulation; defining characteristics of building performance, such as human response to time-varying noise; and developing methods for comparing benefits and costs, such as life-cycle cost approaches for selecting optimal energy retrofit measures. All these activities are conducted in cooperation with other organizations in the building community that participate in the studies or are affected by the results.

CBT does not promulgate building codes or standards. CBT provides an objective source of technical information for national consensus standards and model code organizations. Close cooperation with these groups leads to standard practices that meet the needs of the regulatory authorities of State and local governments. Research providing the knowledge for these standard practices is conducted in cooperation with Government, university, and industry laboratories.

This report summarizes CBT's research for 1980-1981. Each summary lists the project title, its progress, point of contact within CBT, and sponsor.

The summaries are arranged according to the research areas that comprise the scope of work at CBT, which is shown on page xi. The report has a Building Community Index (p. 74), which keys CBT research to individual segments of the industry.

The reader is encouraged to review two companion documents: NBS Special Publication 439-1 The Center for Building Technology: A Perspective which presents the Center's approach to building research and its facilities; and NBS Special Publication 457, Building Technology Publications, and its supplements.

As they are produced, reports detailing results of these projects will be listed in future issues of Building Technology Publications. 



\section{Contents}

\section{Building Economics}

\section{Building Rehabilitation Technology}

Building and Community Acoustics

Lighting Technology

\section{Building Service Systems Performance}

\section{Structures and Foundations Performance}

2 Economic Methods for Building Standards

Economic Measures of Productivity in the Construction Industry

Economic Impact of NBS Electronics Research Effort

4 Application of Equivalency Methods to Regulations

Related to Health and Sanitation

Regulatory Provisions for Existing Buildings

Restoration Standards for Porcelain Finishes

5 Monitoring the White House Restoration

Quick-Response Studies for HUD

Development of Architectural Accessibility Guidelines

$8 \quad$ Building Acoustics Technology

Highway Noise Criteria

Sound Absorption Measurement

9 Technical Support to the EPA

12 Lighting Technology

Task Lighting Criteria

13 Measurement of Illumination Systems Effectiveness

Laboratory and Field Illumination Measurements

Chromatic Adaptation

14 Visual Acuity Requirements for Nondestructive Testing

16 Performance of Water-Conserving Devices

User Acceptance of Water Conservation

Guidelines for Limited Venting and Single-Stack

Drainage Systems

17 Solid Transport in Horizontal Drains

Plumbing Vent Systems Network Analysis

18 Service Life of Electrical Wire Insulation

20 Criteria for Structural Loads and Design

21

Snow Loads on Nuclear Power Plant Structures

Application of Life-Test Analysis Concepts to

Building Components

CBT Wind Tunnel: Performance Criteria and

Final Design

22 Criteria for Design of Cladding Subjected to Wind Loads

Performance of Residential Siding

Construction of Housing in Mine-Subsidence Areas

23 Requirements and Format for the Siting of LNG

Facilities

Foundation and Excavation Standards

Geotechnical Measurements of In-Situ Soil Properties 
24 Ultimate Limit States for Joints and Fasteners in Light-Frame Construction

Reliability-Based Design of Containments and Category I Structures

25 Anchoring Mechanics for Mobile Homes Mobile Home Anchoring in Flood Plains

26 NDE of Building Materials

NDE for Concrete Strength

Interpretation of Ultrasonic NDE Results

27 Cement Hydration

28 Organic Coatings

Fly Ash Use in Cement and Concrete Products

Corrosion of Steel in Prestressed Concrete

29 Short-Term Evaluation of Steel Coatings

Field Adhesion Tester

30 Measurements and Standards for Nuclear Waste Management

Tri-Services Technical and Scientific Support

Earthquake Hazard Reduction

Building Safety
32

33

34
Seismic Provisions for Buildings

Seismic Limit-States for Structures

Romania Earthquake Rehabilitation

Computer-Controlled Test Facility

Cyclic-Loading of Masonry Building Components Cyclic-Strain Approach to the Determination of

Liquefaction Potential of Level Sandy Sites Improving the Standard Penetration Test as a

Measure of the Liquefaction Potential of Sands

Construction Load Evaluation

Excavation Safety

Effectiveness Evaluation of Symbol Use

Effectiveness of Safety Symbols in the Workplace

Building Circulation Evaluation System: Phase I

Modeling Occupant Circulation Systems

The Use of Hazard Pictorials/Symbols in Mines

Technical Support for Correctional Facilities

Design Standards

Energy Conservation in Buildings

Building Energy Performance Criteria

Integrated Energy Systems

Energy Analysis Procedures

43 Energy Analysis of the Norris Cotton Building

Energy Analysis of Control Strategies

44 Thermostat Test Standard

CBT Controls Laboratory

45 EMCS Algorithms

EMCS Measured Performance

Retrofit Instrumentation Technology/EMCS Sensors

46 Dynamic Performance of HVAC Systems and Controls 
Laboratory Tests for Thermographic Standards

Air Infiltration in Large Buildings

47 Evaluating the Performance of Heat Pumps

Heat Pump and Air Conditioner Test Procedures

48 Furnace and Boiler Test Series

Underground Heat Distribution Systems

Daylighting Prediction

49 Radon Transport in Building Materials

Building Thermal Envelope Systems and Insulating Materials

52 Thermal Conductivity Apparatus

Thick Insulation Test Series

Thermal Insulation Analysis

Calibrated Hot Box Construction

53 Calibrated Specimen Round-Robin Tests

Multi-Room Thermal Modeling

Installation Criteria for Building Retrofit

Field Measurements of Building Thermal Mass

54 Guidelines for Controlling Attic Condensation

Field Determination of Wire Temperatures
Building Solar Systems Technology $\mathbf{5 6}$

\section{Passive Solar Data Requirements}

Collector Durability and Reliability Test Program

Standards for Solar Absorptive Coatings

Standards for Solar Cover Plates

Standards for Optical Property Measurements

Thermal Test Methods for Solar Collectors

Test and Evaluation of Solar Collectors

Standards for Nonmetallic Containment Materials

Standards for Rubber Hose and Connections

Standards for Phase-Change Storage Materials

Thermal Energy Storage and Building Codes

Development of Solar Regulatory Provisions

Cement Hydrates for Energy Storage

Solar Energy Program for Housing Systems

Kinetics of Glycol-Based Antifreeze Degradataion

Evaluation of IPC Corrosion Test Methodology

Solar Hot Water System Test Program

\section{Buildings}

Health and Safety Criteria for Passive Solar Systems

Modeling for the Analysis of Thermal Comfort in

Passive Solar Buildings

Thermal Test Methods for Passive Components

64 Modeling of Passive Solar Buildings

Standards for Passive Solar Materials, Components, and Systems

The Influence of Micro-Changes on the Engineering Properties of Solar Materials

65 Materials Problem Definition: Solar Industrial

Process Heat Applications

The Industry Impact of Solar Equipn ent Standards

Economic Consultation for the Solar Federal Buildings Program 
Economic Evaluation Framework

Comparison of Selected Solar Economic Evaluation Models

67 Cost-Benefit Studies of Solar Federal Building Projects

Residential Solar Data Center

Solar Systems User Data Base

68 Federal Guide Specifications for Solar Heating and Hot Water Applications

Reliability and Maintainability of Solar Heating and Cooling Systems

Performance Criteria for Solar Heating and Cooling Systems in Commercial Buildings

69 Technical Assessment of Buildings Being Considered for Solar Retrofit

Thermal Performance Data Requirements and Evaluation Procedures

Solar Utilization in Cities and Towns

70 Commercial Solar Energy Demonstration

Monitoring of Radon Concentration in Passive Solar Buildings

71 Technical Support to the Solar Standards Committee International Cooperation in Solar Energy 


\section{Abbreviations Used in the Text}

$\mathrm{ACF}$

AID

ACI

AIA

AIARC

ANMC

ANSI

ARI

ASCE

ASPE

ASSE

ASTM

ASHRAE

ASME

BECC

BFIRES

BLAST

BOCA

BRAB

BUR

CAM

CBT

CERL

CFR

CIB

CICC

CSA

CPSC

DoD

DoE

EDA

EIA

EMCS

EPA

FAA

FCC

FEMA

FERC

FmHA

FHWA

FIRL

FSES

GSA

HHS

HID

HUD

HVAC

ICBO

IEEE

IERI

Area Cost Factors

Agency for International Development

American Concrete Institute

American Institute of Architects

AIA Research Corporation

American National Metric Council

American National Standards Institute

American Research Institute

American Society of Civil Engineers

American Society of Plumbing Engineers

American Society of Sanitary Engineers

American Society for Testing and Materials

American Society for Heating, Refrigerating, and Air-Conditioning Engineers

American Society for Mechanical Engineers

Building Energy Conservation Criteria

A Computer Program Dealing with Human

Performance During Building Fires

An Energy Analysis Computer Program

Building Officials and Code Administrators International, Inc.

Building Research Advisory Board

Built-up Roofing

Center for Applied Mathematics (NBS)

Center for Building Technology

Construction Engineering Research Laboratory (U.S. Army)

Center for Fire Research (NBS)

International Council for Building Research, Studies, and Documentation

Construction Industries Coordinating Committee

Community Service Administration

Consumer Product Safety Commission

Department of Defense

Department of Energy

Economic Development Administration

Energy Information Agency

Energy Monitoring and Control Systems

Environmental Protection Agency

Federal Aviation Administration

Federal Construction Council

Federal Emergency Management Agency

Federal Energy Regulatory Commission

Farmers Home Administration

Federal Highway Administration

Franklin Institute Research Laboratories

Fire Safety Evaluation System

General Services Administration

Department of Health and Human Services

High Intensity Discharge

Department of Housing and Urban Development

Heating, Ventilation, and Air-Conditioning

International Conference of Building Officials

Institute of Electrical and Electronic Engineers

Illumination Engineering Research Institute 


$\begin{array}{ll}\text { IES } & \text { Illumination Engineering Society } \\ \text { ISO } & \text { International Standards Organization } \\ \text { LBL } & \text { Lawrence Berkeley Laboratory } \\ \text { LCC } & \text { Life-Cycle Costing } \\ \text { LNG } & \text { Liquid Natural Gas } \\ \text { MIMA } & \text { Mineral Insulation Manufacturer Association } \\ \text { MIUS } & \text { Modular Integrated Utility Systems } \\ \text { MPS } & \text { Minimum Property Standards } \\ \text { NAHP } & \text { National Association of Home Builders } \\ \text { NBS } & \text { National Bureau of Standards } \\ \text { NBSLD } & \text { National Bureau of Standards Load Determination } \\ & \quad \text { (A Computer Program) } \\ \text { NCSBCS } & \text { National Conference of States on Building Codes } \\ & \quad \text { and Standards } \\ \text { NDE } & \text { Nondestructive Evaluation } \\ \text { NEC } & \text { National Electric Code } \\ \text { NEMA } & \text { National Electrical Manufacturers Association } \\ \text { NFPA } & \text { National Fire Protection Association } \\ \text { NIBS } & \text { National Institute of Building Sciences } \\ \text { NIOSH } & \text { National Institutes of Occupational Safety } \\ & \quad \text { and Health } \\ \text { NOAA } & \text { National Oceanic and Atmospheric Administration } \\ \text { NPS } & \text { National Park Service } \\ \text { NRC } & \text { Nuclear Regulatory Commission } \\ \text { NRCC } & \text { National Research Council (Canada) } \\ \text { NSF } & \text { National Science Foundation } \\ \text { ORNL } & \text { Oak Ridge National Laboratory } \\ \text { OSHA } & \text { Occupational Safety and Health Administration } \\ \text { RCS } & \text { Residential Conservation Service } \\ \text { RIF } & \text { Resource Impact Factors } \\ \text { RILEM } & \text { International Union of Testing and Research } \\ & \text { Laboratories for Materials and Structures } \\ \text { RSV } & \text { Reduced-Size Venting } \\ \text { SAE } & \text { Society for Automotive Engineers } \\ \text { SERI } & \text { Solar Energy Research Institute } \\ \text { SPT } & \text { Standard Penetration Tests } \\ \text { SRM } & \text { Standard Reference Materials } \\ \text { TIFS } & \text { Thermal Indicating Flexible Strips } \\ \text { UF } & \text { Urea-Formaldehyde } \\ \text { USGS } & \text { United States Geological Survey } \\ \text { USNC/CIB } & \text { United States National Committee/International } \\ & \text { Veterans Administration } \\ & \end{array}$




\section{CENTER FOR \\ BUILDING TECHNOLOGY}

\section{CENTER HEADQUARTERS}

\section{Structures and Materials Division}

Earthquake Hazards Construction Safety Geotechnical Engineering

Structural Engineering

Building Materials

Building Composites

Environmental

Design Research Division

Architectural Research

Sensory Environment

Building Safety

Building and Community Acoustics

Building Economics and Regulatory Technology Division

Applied Economics

Building Rehabilitation Technology

Solar Technology

Criteria and

Standards Development

Thermal Analysis

Passive Solar Systems

Thermal Insulation

\section{Building Equipment Division}

Thermal Machinery

Systems and Controls

Service Systems

Active Solar Systems 

Buñoling EGomomics

Building EGOMomics

Building Economics

Bund|ling EGonomics

Building EGonomics

Bund/ding EGonomics

Buniding EConomics

Buadding EGonomics

Bund-ding EGomonics

Buadding EGonomics

Buñ|ding EGonomics

Buid/ding EGonomics

Buddoling EG Eonomics

Bundoling EGomomics 


\section{Economic Methods for Building Standards}

Harold E. Marshall

(301) 921-3701

Building Economics and Regulatory

Technology Division

Sponsor: National Bureau of Standards

Economic Measures of Productivity in the Construction Industry

Stephen F. Weber

(301) 921-2308

Building Economics and Regulatory

Technology Division

Sponsor: National Bureau of Standards

\section{Economic Impact of NBS Electronics Research Effort}

Carol C. Rawie

(301) 921-3602

Building Economics and Regulatory

Technology Division

Sponsor: National Bureau of Standards
In this project, methods for life-cycle cost analysis and benefit-cost analysis will be specially developed for application to building problems. The Savings-toInvestment Ratio Technique will be described and published in draft form suitable for consideration by ASTM as a standard recommended practice. Technical services will be provided to the ASTM E-6.81 Subcommittee on Building Economics to develop standardized economic methods and definitions. Technical support will also be provided to the CIB W55 Working Commission on Building Economics.

The first stage of this project is devoted to reviewing the considerable body of economic literature on the measurement and analysis of productivity as well as on the theory of index numbers. The purpose of this review is to provide a solid theoretical basis for the productivity measures to be developed and applied to construction activities. The next stage involves a thorough search for all relevant data sources concerning productivity in the construction industry. The third stage is devoted to identifying a specific construction activity or process for detailed productivity analysis. For the selected process, standardized measures of output and of each of the factor inputs (e.g., labor, materials, and capital equipment) are to be developed in the fourth stage. The fifth stage of the project involves the construction of productivity indexes designed to measure changes in the levels of productivity for each of the factors of production. The final stage of the project is devoted to writing a report explaining the productivity indexes and their underlying theory and applications.

Because of the scarcity of funds available for research, there is increasing need for Government agencies, including scientific agencies such as NBS, to be aware of the economic impacts of their activities. But measuring economic impacts of Government scientific research is difficult, partly because the information that results is usually distributed freely rather than being bought and sold like ordinary goods. Thus, NBS managers need a workable method for measuring the economic impacts of their research projects. The purpose of this study is to develop and apply a method of estimating economic impacts of NBS research. It will do so through a case study of the economic impacts of a research effort in the Center for Electronics and Electrical Engineering. 


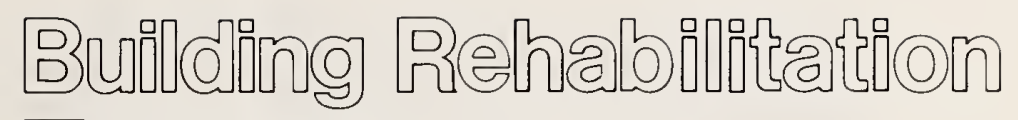
Technology

\section{Building Rehabilitation Technology}

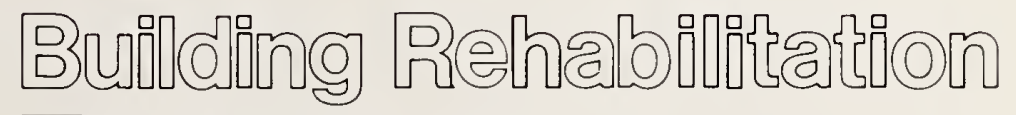
Technology

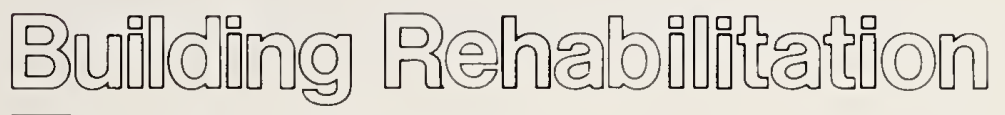
Technology

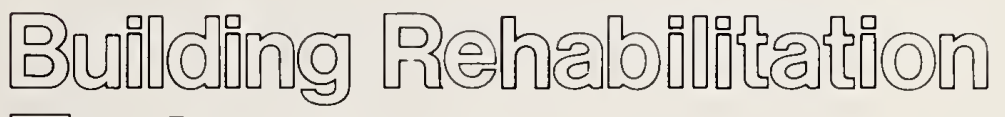
Technology

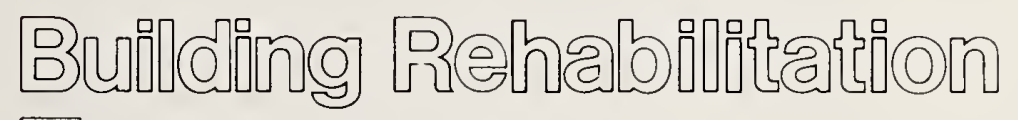
Technollogy

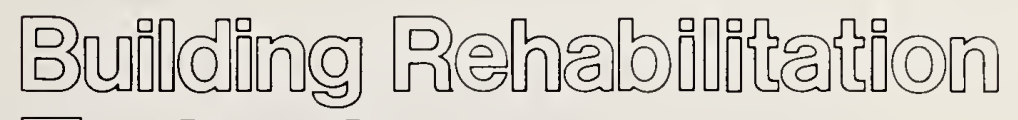
Technology

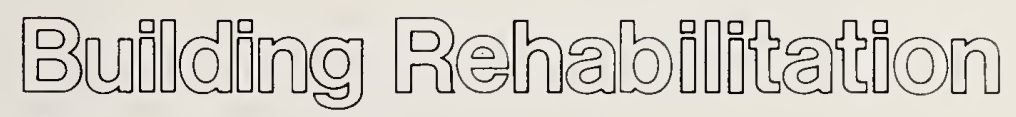
Technology

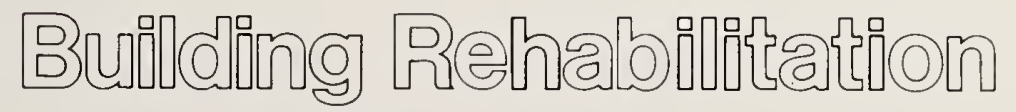
Technology 
Application of Equivalency Methods to Regulations Related to Health and Sanitation

James H. Pielert

(301) 921-3146

Building Economics and Regulatory

Technology Division

Sponsor: National Bureau of Standards

\section{Regulatory Provisions for Existing Buildings}

James H. Pielert

(301) 921-3146

Building Economics and Regulatory

Technology Division

Sponsor: National Bureau of Standards

\section{Restoration Standards for Porcelain Finishes}

James F. Seiler

(301) 921-2909

Structures and Materials Division

Sponsor: Department of Housing and Urban Development
This project, jointly carried out by CBT and CAM, will develop and explore the application of an equivalency method similar to the Fire Safety Evaluation System (FSES) to health and sanitation. Combined application of the FSES currently under development by CFR for multifamily residences and health and sanitation criteria will be studied. This will build on a pilot study jointly carried out by CBT and CAM in FY 80 on the application of equivalency techniques for lighting, security, egress, and ventilation of windows and doors in existing buildings. Mathematical solutions developed in the pilot study will be used and modified where necessary by CAM. The initial activity will be to agree on parameters, functional requirements and states to be considered in health and sanitation. A fault tree that identifies the physical parameters will be developed. An internal NBS delphi group will be formed to develop agreement on numerical values. The baseline requirements will be selected based on data in NBSIR 80 2081, Comparison of Selected Codes and Standards Relating to Existing Buildings. Cost impacts will be included in the analysis in arriving at least-cost code complying solutions.

The efficient reuse of existing buildings can be promoted by the development and implementation of information required to make technical decisions. This project involves technical support in the development of regulatory provisions for existing buildings. CBT provides technical and secretariat support to the ASCE Standards Committee, "Condition Assessment of Structural Systems in Existing Buildings" CBT also sponsors the annual NBS/NCSBCS Joint Conference on Research and Innovation in the Building Regulatory Process, and publishes the results of the technical sessions. This year, a Federal workshop on Building Rehabilitation will be held.

The maintenance of porcelain enameled fixtures has been a major concern to HUD. Restoration of fixtures by application of organic coatings to the damaged porcelain surfaces may cost one quarter as much as replacement. The evaluation of the performance of commercially available finishes, recommendations for performance criteria for their selection, and application standards are essential for the successful use of these finishes. To fill this gap, CBT will evaluate the performance of restoration finishes by laboratory test methods. Laboratory data will provide the technical basis for performance criteria for these materials. 


\section{Monitoring the White House \\ Restoration}

Larry W. Masters

(301) 921-3458

Structures and Materials Division

Sponsor: National Park Service

\section{Quick-Response Studies for HUD}

Joseph Greenberg

(301) 921-3147

Building Economics and Regulatory

Technology Division

Sponsor: Department of Housing and Urban Development

\section{Development of Architectural Accessibility Guidelines}

\section{Sanford Adler}

(301) 921-2574

Environmental Design Research Division

Sponsor: Architectural and Transportation Barriers Compliance Board
The 1980 White House restoration was carried out in accordance with specifications developed by CBT. These specifications are expected to be the prototype for subsequent White House restorations. To gather performance data needed to revise the specifications for exterior coatings and related materials, it is essential to monitor the 1980 restoration. Inspections and analyses by CBT personnel will supplement related NPS activities, which include photography and photogrammetry.

During FY81, CBT will be called upon for specific answers to questions on building technology. In the past, CBT has conducted performance tests on questionable materials or assemblies, a racking test on a panel wall, testing a soil for the leaching of termite poison, making air-quality tests in homes where asbestos materials have been used, measuring the capability of an in-situ brick testing device, writing a state-of-the-art report on plumbing trees, and developing criteria for hallway width.

National concern for the rights of disabled Americans to reasonable access to buildings has been expressed by the Architectural Barriers Act of 1968 and the Rehabilitation Act of 1973. The current proliferation of accessibility guides and codes at the Federal, State, and local level has resulted in a number of inconsistent or conflicting documents that have placed a significant burden on the building industry. In this project, accessibility guidelines will be developed that consider not only the needs of the building user but also the realities of architectural and construction practices in the United States. FY80 activity focused on documenting areas of disagreement in existing accessibility requirements, and identifying areas of needed research. In addition, research on door-operating forces was begun. Work in FY81 will focus on research to eliminate areas of ignorance and disagreement in existing accessibility requirements. Research on dooroperating forces will be continued and instrumentation will be developed for field use. 

Building and Community Aleoustics

\section{Building and Community Acoustics}

Budiding and Communify Aleoustres

Buㅁำing and Community AGoustics

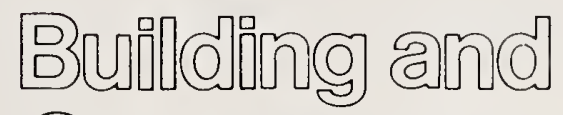
Communuity Aleoustics

Budiding and

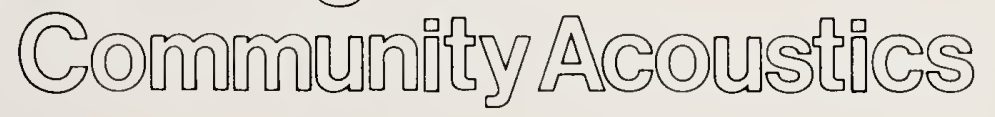

Buำling and Community Aseursties

Buidoling and Communnify Algoustices

Builfoling and Communnity Aseursties 


\section{Building Acoustics Technology}

Simone L. Yaniv

(301) 921-3783

Environmental Design Research Division

Sponsor: National Bureau of Standards

Highway Noise Criteria

Jay W. Bauer

(301) 921.3783

Environmental Design Research Division

Sponsor: Federal Highway

Administration

\section{Sound Absorption Measurement}

Thomas W. Bartel

(301) 921.3783

Environmental Design Research Division

Sponsor: National Bureau of Standards
Acoustical treatment and noise management can cause large increases in building costs if not incorporated early in the basic design. Corrective construction in existing buildings is especially costly. Nevertheless, these steps are taken because of the negative effects of inferior acoustical performance on occupant satisfaction and worker productivity. These costs can be lowered and sometimes offset by operational savings over a building's life cycle if decisions about site and building design, construction, and operations are made with regard to acoustical consideration. This project will develop design criteria for noise isolation of building spaces. Acoustic parameters affecting user responses will be identified through limited sampling of outdoor environments, building types, construction parameters, and achieved isolation. Using these data, psychoacoustic studies will be conducted under controlled laboratory conditions to provide technical bases for specifications of noise isolation of building shells and party walls. Outdoor-toindoor measurement methods will be developed by characterizing sound fields in and around buildings by land-use, location, orientation of buildings relative to noise sources, and building configuration.

Field data have been collected and analyzed on the time histories and spectra of traffic noise and on how traffic sounds are received in a building. Laboratory investigations are underway on the human response to the time-varying noises obtained previously. From analysis of the data collected in these psychoacoustic experiments and in conjunction with the analysis done on the physical data base, an evaluation of existing rating schemes will be conducted. If necessary, an improved rating procedure will be developed. A questionnaire and measurement plan will be developed to assess occupant reaction to highway noise based on the key parameters identified in the project.

Using the NBS Sound Building's reverberation chamber, a direct method for measuring sound absorption will be developed and compared with results obtained using the current method based on reverberation time. This method will then be modified for practical field applications to account for the effects of field conditions. In addition, to improve indoor acoustic predictions, the validity of the "Sabine relationships" - which undergird modern acoustical theory and practice in relating reverberation time, acoustical absorption, radiated sound power, and interior sound pressure levels-will be examined to test the assumptions inherent in the Sabine equations. To that effect, several techniques will be developed, including time-energy-frequency analysis, statistical energy analysis, and scale-model techniques. 
Based upon studies performed in the reverberation room, in scale-model rooms, and formal solutions to wave equation and finite element solutions, corrections will be developed for the Sabine relationships for both reverberant and semi-reverberant fields. The work will proceed from the reverberation room to the listening room and then to actual buildings.

\section{Technical Support to the EPA}

Simone Yaniv

(301) 921.3783

Environmental Design Research Division

Sponsor: Environmental Protection

Agency
Noise is consistently identified in social surveys as a major concern of building occupants and community residents. Noise also has a negative effect on occupant productivity. EPA's enforcement of the Noise Control Act of 1972 and the Quiet Communities Act of 1978 requires investigation of the effects of noise intrusion into building environments. CBT will support that work by providing EPA with the technical assistance necessary to support its noise program requirements. In addition, the physical noise parameters intruding into buildings will be identified and an experimental approach to studying their effects on people developed. By developing a pilot study design, the effects of intrusive noise on building occupants will be reviewed with the objective of developing refined experimental methods for their study. These refined experimental methods will provide the data bases required to improve building design and to enhance the productivity of the building user. 



\section{Liginthing Technology}

Lighrhthing Techno|logy

\section{Lighting Technology}

Lighthing Technology

Lighthing Technology

Lighithing Technology

Lighthong Technology

Lighthing Technology

Lighthing Technology

Lighthing TeGhrology

Lig|hrtho Techro|logy

Lighthing Technology

Lighthing Techno|logy

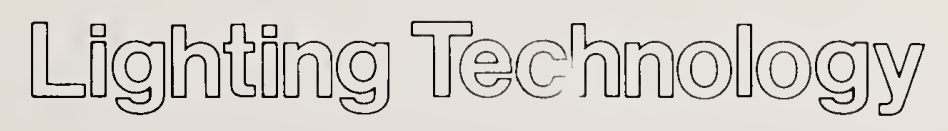




\section{Lighting Technology}

Gary T. Yonemura

(301) 921-2680

Environmental Design Research Division

Sponsor: Department of Energy

Task Lighting Criteria

Gary T. Yonemura

(301) $921-2680$

Environmental Design Research Division

Sponsor: Department of Energy
Laboratory research at NBS, first using grating patterns, and then employing printed matter (realistic tasks), indicates that when visual sensitivity is measured by conspicuity of details, the function relating luminance with contrast is different from that obtained when the visual task is threshold detection only. An apparatus to assess conspicuities of typical office tasks relative to a reference five-bar target will be constructed. A modified form of this device will also be built for obtaining conspicuity function data faster and easier. A three-day conference, jointly sponsored by IES and NBS, was conducted in January 1981. The conference took the form of 90 workshops-each one dealing with a major lighting issue. Each workshop chairman is responsible for preparing a report describing research and application requirements for the next decade. These reports will be used to prepare an integrated, comprehensive 10-year plan of research into lighting design, use, and evaluation.

Laboratory research at CBT, first using grating patterns and then employing printed matter (realistic tasks), indicates that when visual sensitivity is measured by conspicuity of details, the function relating luminance with apparent contrast is different from that obtained when the visual task is threshold detection, the classical basis for recommending illumination levels. Additional experiments will be conducted at these suprathreshold levels to determine more specifically the form of the suprathreshold visibility-luminance functions and the level of visibility necessary for sustained performance of office tasks under conditions simulating the real world. Sample office tasks will be evaluated for visibility levels, relative to a five-bar reference target. These data are also necessary to determine the minimum number of light levels that must be considered for offices. Minimizing the number of light-level recommendations for offices will be helpful in promulgating energy conservation codes, where simplicity is a strong selling point for acceptance. The findings will be presented to the Illuminating Engineering Research Institute, Energy Management Committee, and the Recommendation of Quality and Quantity of Light (RQQ) Committee of the IES, in presentations at the IES Regional Conference, and articles in the IES Journal. 
Measurement of Illumination Systems Effectiveness

A. Ted Hattenburg

(301) 921.3454

Building Thermal Performance Division

Sponsor: National Bureau of Standards

\section{Laboratory and Field Illumination Measurements}

\section{A. Ted Hattenburg}

(301) 921-3454

Building Thermal Performance Division

Sponsor: National Bureau of Standards

\section{Chromatic Adaptation}

Robert A. Glass

(301) 921.2246

Environmental Design Research Division

Sponsor: National Bureau of Standards
Energy used for illumination accounts for about 6 percent of total U.S. consumption, and 25 percent of electrical generation. Past reliance upon simplistic illuminance measurements, poorly defined reflectance values, and complex calculation schemes based upon inadequate data have hampered efforts to evaluate the actual performance of illumination systems designed to conserve energy. Under this project, the contrast rendition factor of a number of installed office lighting systems will be determined by use of a laboratorydeveloped field measurement technique, using a calibrated modest-cost commercial luminance spotmeter and reproducible standard targets developed under an associated NBS project. A procedure manual will be written to allow untrained personnel to use the field measurement technique. The reflectance properties of the targets will be determined for use in predictive calculations for the design of lighting systems to specified contrast-rendition conditions.

Building illumination practice has relied upon simplistic measurements of illumination levels, poorly defined reflectance values, and complex calculation schemes based upon inadequate data. The new requirements for more cost-effective, energy conserving illumination systems are creating a demand for more precise, valid physical measurement techniques to guide systems design, evaluate the effectiveness of prototype and installed lighting systems, and contribute to the physical basis of vision research. The development of precise physical-measurement techniques in illumination under this project will directly support voluntary standards and advances in vision and illumination (artificial and natural) research.

Recent work conducted at CBT has shown that under high-efficacy illumination systems, the effects on chromatic adaptation (color perception) persist as long as 23 minutes when workers have been in typical office illumination levels (about $60 \mathrm{ft}-\mathrm{C}$ ) for 45 minutes or more. These findings provide new information on this topic and may explain the adverse response of many people who work under HID lamps in office environments-e.g., occupants of the Federal Building in Manchester, NH. Research is currently underway to more precisely quantify these effects. 


\section{Visual Acuity Requirements for Nondestructive Testing}

Gary $\mathrm{T}$. Yonemura

(301) $921-2680$

Environmental Design Research Division

Sponsor: Department of Defense
Much is known about the visual processes, but the visual conditions, techniques, and information capacity required of the inspector, as specifically related to NDT, are not established. Discussions will be held with DoD personnel on types of tasks and levels of difficulty encountered in DoD's nondestructive testing programs. Based on the evaluation of the different types of acuity tests currently being used, acuity measurement targets and testing techniques will be recommended. The possibility of making revised visual acuity test charts available as NBS Standard Reference Materials (SRM) will be considered. The output of this research will be a recommended practice and visual acuity capacity required for practical radiograph inspection. These inspections are increasingly used to evaluate building materials and components. The recommendations from this work will serve as basis for a measurement procedure to be implemented by the Opthalmology Departments of the Army Materials and Mechanics Research Center Medical Departments. Standard test stimuli and methods used for testing the visual performance capability of inspectors using NDT procedures where the human eye is the measurement instrument will assist in greater agreement between different groups performing similar visual tasks, resulting in better quality control and safety for products. 
Bundoling Service. Systems Performance

\section{Building Service Systems \\ Performance}

Buofolding Service Systems

Perpornance

Bupholng Servịce

Systems

Perpornance

Bundoling Service

Systems

Perromance

Buildong Service

Systems

Performance 


\section{Performance of Water-Conserving Devices}

Lawrence S. Galowin

(301) 921-3293

Building Equipment Division

Sponsor: Department of Housing and Urban Development

\section{User Acceptance of Water Conservation}

Jacqueline Elder

(301) 921-2246

Environmental Design Research Division

Sponsor: Department of Housing and Urban Development
The clear need for a national water conservation policy implies a concomitant need for methods of evaluation, development of predictive design methods, standards, recommendations, and incentives for reduced water usage. Water reduction requirements are being promulgated by local and state regulatory bodies without the minimum satisfactory levels of performance derived from hydraulic investigations, economic consequences, or user acceptance levels. HUD is sponsoring the development of guideline criteria and test methods for water conservation requirements in codes and the Minimum Property Standards. Community and water utility decisions about water conservation programs require public understanding of conservation practices. Performance requirements, test methods, and evaluation procedures will be developed based upon laboratory research to provide a basis for consensus standards. Guidelines and criteria will be established for hydraulic effectiveness with water reduction, economic basis for decisions, and evaluation of incentives and motivation for acceptance of water conservation.

A recently completed literature review indicates that reliable quantified data have not been established from field research in the area of occupant response to specific water conservation devices. The laboratory-based hydraulic parameters associated with showerheads have been established. However, it is not known how to relate those parameters to consumer requirements. Showerhead manufacturers and HUD officials have indicated the need for data relating the physical characteristics of showerheads to user response. This project will conduct a pilot study to evaluate user response to specific showerheads. Showerheads instrumented to measure water pressure and temperature will be distributed to volunteers. The data records will include the instrument readings and a record of the duration of each shower and also provide specific responses and open-ended commentary. At the study's end, an attempt will be made to correlate laboratory-determined hydraulic parameters with user acceptance.

Current plumbing criteria require prevention of trap seal failure by venting. Systems without separate venting are satisfactory in performance as demonstrated in Philadelphia, throughout Europe, and in special single stack systems (i.e., Sovent). Particular installations may be permitted through justification and demonstration under regulatory variance processes. However, the acceptability in the United States is relatively low because of traditionally conservative plumbing codes and a reluctance to accept innovations. Safe installations with limited venting are required for economic rehabilitation. 


\section{Solid Transport in Horizontal Drains}

Bal M. Mahajan

(301) 921.2028

Building Equipment Division

Sponsor: National Bureau of Standards

\section{Plumbing Vent Systems Network Analysis}

Paul Kopetka

(301) 921-2136

Building Equipment Division

Sponsor: National Bureau of Standards
Additional drainage stack piping bypass "loops" performing the functions of the splitter of single stack design have the potential of providing increased capacity along with prevention of trap seal failures.

A significant savings of water consumed in buildings can be realized by using low-volume or water-saving water closets. However, the reduction of wastewater flow in the horizontal branches of the drainage system may lead to inadequate transportation of waterborne solid waste. Relatively few studies have been undertaken to investigate the solid transport phenomenon within common horizontal drains. Modeling procedures for predicting the local flow characteristics of the timedependent partially-filled pipe flow through horizontal drains leading to pipe sizing methods will be developed. Also, instrumentation for measuring the flow characteristics in the pipe flow will be refined in an attempt to validate the mathematical models or establish empirical relationships.

No adequate design method generally acceptable to codes and standards groups for incorporating reduced size venting (RSV) into plumbing systems is currently in practice. Present vent system design methods lack a solid engineering foundation, are difficult to understand, and awkward to use. Existing computer vent system design is based upon "fixture-units," supply loads without fixturevent requirements. This approach ignores important flow circulation characteristics and empirical data. Tabulations of vent-fitting loss coefficients over the range of flowbranching conditions and inlet-to-outlet area ratios are incomplete; the accuracy of estimates based on extrapolation of existing data is questionable. In this project, the present network analysis solution technique, limited to three fixture vents, will be expanded. The generalization will provide the capability to model realistic systems, i.e., multi-story buildings, based on steady-state conditions. 


\section{Service Life of Electrical Wire Insulation}

Robert Beausoliel

(301) 921-3454

Building Equipment Division

Sponsor: National Bureau of Standards
Degradation of electrical wire insulation due to aging and heating can lead to electrical short circuiting, which is suspected to be one of the leading causes of fires in buildings. In addition, shock hazards may develop because of degradation of the dielectric insulation. These problems appear to be aggravated when thermal insulation is placed over or next to the electrical wires, e.g., in attics or cavity walls. Studies at CBT have shown that heat generated in the wires by passage of electricity is less rapidly dissipated when they are covered with thermal insulation; in some cases wire temperatures have been found to greatly exceed the allowable operating temperatures of the National Electrical Code. In view of the potential hazards caused by the degradation of residential electrical wiring insulation, information about service life needs to be considered in selecting dielectric materials. Information about service life also would be valuable in estimating the remaining service life of installed electrical wiring. Little information has been reported on the durability of residential electrical wire insulation, and reliable predictions of service life do not appear to be available. The purpose of this project is to use the reliability approach to develop service life predictions for electrical branch circuit wiring. 
Strungitures and Foundanthon Perpormance

\section{Structures}

and Foundations Performance

Strungtures (nd Foundathon Perforname

Strungrunes จnด Foundontons Per\}orñare

Strunchunes and Foundantons Perromanace

Strunchures

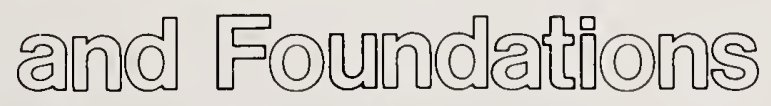
Perfornance 
Criteria for Structural Loads and Design

Bruce R. Elling wood

(301) $921-2170$

Structures and Materials Division

Sponsor: National Bureau of Standards

\section{Snow Loads on Nuclear Power Plant Structures}

Bruce R. Ellingwood

(301) $921-2170$

Structures and Materials Division

Sponsor: Nuclear Regulatory Commission
Current structural design standards rely on different philosophies and criteria for design, depending on the material or construction technology used. This tends to complicate design when different technologies are employed in the same structure. Differences in design philosophy cause a lack of consistency in the reliability levels of different buildings. In recognition of these problems, the trend in Europe and Canada has been toward the development of a common basis for design that would be applicable to all buildings regardless of their material or construction technology. To ensure adequate performance, the unifying concept of limit states has been used, along with a probabilistic treatment of the uncertainties invariably found in engineering design. This project is concerned with the development of design criteria, specifically applicable to building standards in the United States, that will ensure adequate reliability against structural failure and unserviceability. This will lead to reduced building costs by simplifying the design process and stimulating market competition between construction technologies.

Current design standards specify snow loads on roofs by multiplying the ground snow load by a snow load coefficient $\mathrm{C}_{\mathrm{s}}$. In ANSI Standard A58.1-1972, $\mathrm{C}_{\mathrm{s}}$ depends on roof exposure and geometry. Except in valleys of sloped roofs and locations of elevation change, the load is assumed to be uniformly distributed. However, snow seldom accumulates evenly because of drifting and sliding and the loads may not actually be uniform, even on flat roofs. Thermal effects are not included in the determination of $\mathrm{C}_{\mathrm{s}}$, despite evidence that the roof load may be significantly higher for unheated buildings or where the roof is heavily insulated. Finally, the coefficients in A58.1-1972 are based on Canadian studies of ordinary structures: the extent to which these data can be used to represent the different roof geometries in nuclear power plant structures is not clear.

Under this project, technical assistance to NRC to identify roof snow loads and develop loading criteria will proceed in two phases: 1) snow loads on power plant structures will be measured and correlated to ground snow loads for several facilities in the NE quadrant of the United States, and 2) data gathered in phase 1 will be integrated with existing data from similar studies for the purpose of recommending tentative snow-load coefficients for design. A report will be prepared for the NRC giving survey results and recommending snow-load coefficients. 


\section{Application of Life-Test Analysis Concepts to Building Components}

Jonathan Martin

(301) 921.3208

Structures and Materials Division

Sponsor: National Bureau of Standards

CBT Wind Tunnel: Performance Criteria and Final Design

Timothy A. Reinhold

(301) 921.2186

Structures and Materials Division

Sponsor: National Bureau of Standards
If the construction industry continues to use plastics at the present rate, polymers could emerge as the major class of building components of the 21 st century. While this statement reflects the growing optimism for the future role of polymers in construction, there are technical barriers which slow the rate of growth. In particular, the potential thermal and nonthermal degradation of polymers presents a technical barrier. The purpose of this research is to predict the service life, using a reliability physics approach, for polymers subjected to thermal and photolytic stresses. As an adjunct to the research, the Second International Conference on the Durability of Materials and Components will be held at NBS in September of 1981. The conference will provide a medium for exchanging research results relative to the durability of nonmetallic building materials and components.

Three phases of stochastic model development are necessary for this study. The model will be validated at the completion of each phase using data on molecular weight changes which result from the synergistic action of UV light and heat. In the first phase, the stochastic nature of material degradation as a function of time, must be modeled for each thermal and photolytic stress regime. Stochastic processes which include shock and wear models appear to be especially suitable here and will be considered since the absorption of a photon can be viewed as a shock to the material causing a measurable amount of damage. In the second phase of the model, the parameters of the degradation process will be related to the level of photodegradation. The last phase of the model will be to account for the effects on the chemical reaction kinetics from temperature variations. As for changes in irradiance, the parameter of the stochastic model will be related, via an appropriate physical-chemical equation as a function of temperature and irradiance level. The expected end result of this analysis will be the prediction of the service life distribution for all temperature and irradiance levels.

Although significant advances have been made in recent years, computational fluid mechanics as a practical and routine approach to the solution of wind engineering problems appears to be well into the future. Thus, the low-speed, boundary-layer wind tunnel will, over the next several years, continue to be the primary tool for assessing the effects of wind on buildings and other structures. This project will establish a set of wind-tunnel performance criteria based on the anticipated needs of researchers within CBT. A basic design and cost estimate will then be worked up for consideration in FY82. Because of the complex flow situations likely to be encountered in the space available for such a facility, studies on a scale model (probably 1:10) will be considered. 


\section{Criteria for Design of Cladding Subjected to Wind Loads}

Richard D. Marshall

(301) $921-3471$

Structures and Materials Division

Sponsor: National Bureau of Standards

\section{Performance of Residential Siding}

Robert G. Mathey

(301) 921-2629

Structures and Materials Division

Sponsor: Tri-Services Committee

\section{Construction of Housing in Mine- Subsidence Areas}

Felix Y. Yokel

(301) 921-2648

Structures and Materials Division

Sponsor: Department of Housing and Urban Development
Current design criteria for cladding subjected to wind loads are generally recognized to be seriously deficient. The lack of consistency in present criteria results in major economic losses and in major safety hazards. By contrast, uneconomical design of cladding is believed to occur in a large number of design situations. Modern analytical and experimental tools have not yet been used in investigating the reliability of cladding subjected to wind loads. Tools from the fields of wind engineering (aerodynamics of bluff bodies in turbulent boundary layer flows), nonlinear mechanics of plates, structural reliability, and materials testing will be used in this project with a view to developing rational criteria for cladding design. Data from full-scale and wind-tunnel investigations of wind loads on cladding will be reviewed and studies will be conducted to determine additional research needs.

The rapidly increasing use of residential siding materials, both in new construction and maintenance, has led to the urgent need for performance criteria to aid selection of materials. Of particular interest are criteria addressing durability performance. Under this project, performance characteristics will be measured on some 10-year-old siding materials. Laboratory tests will include color and gloss change, adhesion, abrasion resistance, etc. Laboratory tests will also cover the repainting of the aged siding materials. Adhesion tests will be used to determine the compatibility of the coatings to aged substrates.

Many areas in the United States are underlain by abandoned mines, and many more will be undermined in the future. As mine cavities collapse they cause settlement and ground distortions on the surface that may damage or destroy buildings and utilities. Future expansion of coal mining operations, which is planned as a result of the energy crisis, will increase the magnitude of the problem. Many of these subsidence-prone areas are now used or will be used in the future for residential housing development. In a HUD-sponsored project, CBT studied the subsidence problem and suggested criteria for soil exploration, site development, and housing construction in subsidence areas. 


\section{Requirements and Format for the Siting of LNG Facilities}

Lawrence A. Salomone

(301) 921-3128

Structures and Materials Division

Sponsor: Federal Energy Regulatory

Commission

\section{Foundation and Excavation Standards}

Felix Y. Yokel

(301) 921-2648

Structures and Materials Division

Sponsor: National Bureau of Standards

\section{Geotechnical Measurements of In-Situ Soil Properties}

Felix Y. Yokel

(301) 921-2648

Structures and Materials Division

Sponsor: National Bureau of Standards
Liquefied Natural Gas (LNG) facilities, like nuclear power plant facilities, represent a potential hazard to public safety. In the LNG plant the immediate potential hazard is fire and thermal radiation while for the nuclear power plant, the hazard is long-term radiation caused by the loss of containment. Both types of structures are costly and take a long time to build and the economic consequence of shutdown or catastrophic failure can be enormous in both instances. However, in contrast to nuclear power plants there is a lack of a single set of criteria for design and construction of LNG terminals. To meet this need and to expedite the review process, the Federal Energy Regulatory Commission asked CBT to develop a standard format and content for applicants in their submittal of the necessary information required for siting LNG facilities.

This project supports the preparation of consensus standards for foundations and excavations by the Technical Council for Codes and Standards of the American Society of Civil Engineers. Five separate standards are being prepared: driven piles; piers; excavations; shallow foundations; and deep foundations. Drafts are now being prepared by five working committees and will be submitted for ballot to the Committee on Foundation and Excavation Standard (CFES). CBT began this activity and monitored the preparation of initial drafts for the standard under the sponsorship of HUD. CBT now provides the secretariats for this activity and provides the chairmen of CFES and of one of the working committees.

The project will include a two-part study for the evaluation and improvement of structures and foundations performance. The first part is to study the state-of-the-art methods in foundations and excavations work and evaluate and develop a national standard for this work. In the second part of this project, CBT will study a variety of in-situ methods now being used or considered to measure soil properties. The most practical tests will be selected and mathematical models developed that will derive soil moduli from appropriate forcedisplacement relationships. A series of reports on the research will be published. Draft standards for adoption by ASTM will be prepared for those tests which yield reliable and repeatable results. 


\section{Ultimate Limit States for Joints and Fasteners in Light-Frame Construction}

Charles Yancey

(301) $921-3471$

Structures and Materials Division

Sponsor: National Bureau of Standards

\section{Reliability-Based Design of Containments and Category I Structures}

Bruce Ellingwood

(301) 921.2170

Structures and Materials Division

Sponsor: Brookhaven National Laboratory
This project will involve the development of predictive models of ultimate-limit states for joints and fasteners commonly used in light-frame construction. Variations in material properties, defects, and quality of workmanship will be introduced through Monte Carlo techniques. Physical tests for validation will be carried out by subjecting laboratory specimens to static loads as well as to computer-controlled dynamic loads for the simulation of wind and seismic effects. For the first year of this effort, simple shear connections used in contemporary wood frame construction will be modeled using the GIFTS finite elements and graphics package, modified by inclusion of routines to update connection properties through a progression of load cycles. Physical tests will require refined methods for the measurement of slip and recovery of displacements. With the availability of the STAGS software capability in late 1981, modeling will be carried into the nonlinear range.

The integrity and safety of the components and structures comprising nuclear power plants currently are provided for by the appropriate design codes and supplementary requirements. However, these provisions seldom provide guidance as to "how safe" the structures are. The traditional methods of structural design attempt to account for the inevitable variability in the loads, material strengths, in-service environments, and fabrication processes through the use of safety factors, allowable stresses and strains, load factors, etc., as prescribed in the various ASME, ACI, AISC, etc., codes and NRC Standard Review Plans (SRP). However, the deterministic approach in setting these factors results in an unknown and nonuniform (but probably high) reliability against structural failure in major reactor components such as the pressure vessel, containment, etc.

In the nuclear industry there has been an increasing trend toward the use of statistical analysis and probability theory for safety evaluations. This is particularly the case for seismic Category I structures for which rational methods for reliability evaluation of strength and loads are urgently needed. The reliability-based design approach has a number of significant advantages. First, it encourages the designer to be more aware of safety and service-ability aspects of designs. Second, uniform load factors can be established that can be materialindependent; and in addition, strength reduction factors can be established on the basis of material properties and structural functions. Finally, it is a tool for exercising judgment and provides a means for updating standards rationally.

This is a cooperative program between BNL and NBS. NBS will have responsibility for the analysis of service and extreme environmental loads and for developing the 
basic load combination methodology and procedures for calculating the load factors. BNL will have responsibility for analyzing accidental loads, postulating accident scenarios, dynamic structural analysis of the nuclear structures, and testing the design procedure. NBS will develop a statistical data base for service environmental (dead, load, wind, snow, etc.), severe, and extreme loads. Particular emphasis will be placed on a study of the temporal nature of individual loads since this determines their joint occurrence and other significant probabilistic characteristics.

\section{Anchoring Mechanics for Mobile Homes}

Felix Y. Yokel

(301) $921-2648$

Structures and Materials Division

Sponsor: Department of Housing and Urban Development

\section{Mobile Home Anchoring in Flood Plains}

Felix Y. Yokel

(301) 921-2648

Structures and Materials Division

Sponsor: Department of Housing and Urban Development
Next to fire, wind and floods are the leading causes of deaths and injuries to mobile home occupants and damage to mobile home property. Approximately 5,000 units are heavily damaged or destroyed by storms each year. CBT completed studies on wind loads acting on mobile homes, foundation reactions caused by wind and flood loads, and the state-of-the-art in anchoring technology. Subsequently, many more anchors were tested in three soil types: silt, sand, and clay. On the basis of these tests, and the load studies that preceded them, criteria and test methods will be developed that will form the basis for provisions in revised ANSI standard A.119 and in the Federal Mobile Home Construction and Safety Standard.

After major flooding, the soils on many sites in the flood plain remain saturated for a considerable time. This not only increases the probability of another major flood, but also leads to adverse foundation conditions. Mobile homes in all areas need to be anchored to the ground or otherwise secured to resist the sliding and overturning effects of high winds. In addition, mobile homes in flood plains need to be secured against the hydrostatic and hydrodynamic forces associated with floods. The objective of securing these mobile homes is not only to prevent injury to residents and attenuate damage to the mobile home itself, but also to prevent secondary effects associated with the flotation and dislocation of mobile homes, such as jamming of bridges and other obstructions of flow and clogging of navigable waterways which may be needed in an emergency. At present, there are no data on the capacity of soil anchors in submerged soil. An analysis has also not been made of the forces to which mobile homes in flood areas are likely to be subjected or of other foundation criteria such as siting, elevation, protection from floating debris and others. 


\section{NDE of Building Materials}

James R. Clifton

(301) 921-3458

Structures and Materials Division

Sponsor: National Bureau of Standards

\section{NDE for Concrete Strength}

Nicholas J. Carino

(301) 921-2647

Structures and Materials Division

Sponsor: National Bureau of Standards

\section{Interpretation of Ultrasonic NDE Results}

James R. Clifton

(301) 921-2630

Structures and Materials Division

Sponsor: National Bureau of Standards
This project is a study of the existing and proposed methods for nondestructive evaluation of in-place building components and materials. The techniques have increasing usefulness not only in day-to-day construction but also in rehabilitation of older housing stocks and evaluation of buildings after natural disasters such as hurricanes or earthquakes. The results of this project are being brought to the attention of material scientists and material engineers through workshops, presentations at national meetings, and publications.

Although the pullout test has been demonstrated to be a reliable method of determining in-place strength of concrete, its application is limited to cases for which an empirically established calibration relationship between pullout strength and standard cylinder test strength is available. To be useful, test results based on the present ASTM standard on the pullout test method should provide values that represent the strength property of concrete. In this project, a nonlinear finite-element model will be developed and used to investigate the effects of geometry of various pullout schemes on the failure modes and associated stress distributions. Scaled-up physical model tests will be carried out to verify the validity of the finite-element model. Failure-mode analysis of various concretes will be carried out using this model. An optimum geometry for pullout inserts and standard test procedure will be recommended for adoption by the ASTM C 09 committee.

Ultrasonic methods are possibly the most promising NDE methods for rapidly determining the condition of structural materials and components of buildings being rehabilitated. These methods also could be used to evaluate the quality of repair materials and the effectiveness of repair methods. Ultrasonic NDE methods are based on the theory that the direction and amplitude of waves propagating through a solid may be altered when they encounter a discontinuity such as a crack or porosity, or an interface between different densities or elastic moduli. Therefore, it is theoretically possible to determine the extent of cracking, existence of large amounts of porosity, and the degree of deterioration of structural materials such as concrete, by ultrasonic methods. However, results from ultrasonic tests made on concrete are difficult to interpret because of a lack of fundamental understanding of the interactions of waves and the discontinuities found in concrete. Because of the heterogeneity of concrete, the formation of shrinkage cracks, and the normal porosity of concrete, even high-quality concretes contain numerous discontinuities. The purpose of this project is to develop improved understanding of the propagation of 
ultrasonic waves in concrete and to develop relationships between their propagation and discontinuities.

\section{Cement Hydration}

Geoffrey Frohnsdorff

(301) 921-3458

Structures and Materials Division

Sponsor: National Bureau of Standards

Fly Ash Use in Cement and Concrete Products

James R. Clifton

(301) 921-3458

Structures and Materials Division

Sponsor: National Bureau of Standards
The objective of this project is to develop a fundamental understanding of reactions of portland and related silicate cements with water and develop mathematical models for predicting the courses of the reactions under various conditions in the practical range. The work will begin with studies of the hydration of various preparations of the most important solid phase in portland cements, tricalcium silicate, and later be extended to other cement phases and mixtures of phases. The work will consist of simultaneous development of two or more fundamental mathematical models based on alternative conceptual models. The mathematical models will be tested experimentally and revised as needed. Tricalcium silicates to be used as starting materials will be obtained from the few available sources and some will be manufactured in the laboratory. They will be characterized in terms such as chemical composition, particle size and shape distribution, specific surface area, crystallite size, crystal defects, and grain boundary compositions. The materials will be reacted with water and solutions of ionic and non-ionic compounds to determine the effects of temperature, and water-solid and water-surface area ratios on the mechanisms and kinetics of the reactions. Techniques to be used in studying the mechanisms and kinetics, starting from the moment of mixing, will be electrokinetic phenomena, heat evolution, volume change, electrical conductivity, $x$-ray diffraction, differential scanning calorimetry, surface area measurements by gas adsorption, image analysis, and chemical analysis of the aqueous phase.

The stockpiling and disposal of fly ash are becoming increasingly more objectionable and subject to governmental regulations because of their effect on the environment. Over 60 million tons of fly ash will be generated in 1981. About 300 million tons of fly ash have already been stockpiled. Use of fly ash in cement, concrete, and related products can potentially consume large amounts of fly ash. At present less than 7 million tons/year of fly ash are being used in cement and concrete products, whereas 20 million tons/years seems a realistic goal. The purpose of this project is to identify technical obstacles to the increased use of fly ash in cement and concrete products and to develop a research plan to overcome these obstacles. As a first task, existing and potential uses of fly ash in cement and concrete materials will be identified. At the same time, potential levels of fly ash use in blended cemert $;$, ready-mixed concrete, and precast concrete produc s will be estimated. This will be based largely $\mathrm{c} n$ considerations of 


\section{Organic Coatings}

Mary E. McKnight

(301) 921.2635

Structures and Materials Division

Sponsor: Tri-Services Committee

\section{Corrosion of Steel in Prestressed Concrete}

James R. Clifton

(301) 921-3458

Structures and Materials Division

Sponsor: Department of State the match between the chemistry of fly ash and raw materials or ingredients of these construction materials, the effect of fly ash on product performance and durability, as well as the possibilities for expanding fly ash use. Later, barriers posed by technical factors, and codes and standards to the increased use of fly ash in concrete materials will be identified. Fundamental research needed to overcome these barriers will be outlined. This effort will address individually the construction materials identified, and initially will include both bituminous and lignite fly ashes.

The annual costs of organic coatings in the United States exceed $\$ 8$ billion. Maintenance costs alone would be significantly reduced if better systems, including surface preparation, were available. In developing test methods and specifications, this project contributes directly to the improvement of the coatings technology used by the military and also contributes to improvement of the Nation's coatings technology through publications, specifications, and participation in ASTM activities. The performance and other characteristics of new organic coating systems will be investigated and test methods developed or modified to assay the performance of these materials. Research will be performed to develop improved field tests for coatings evaluation, study the degradation mechanisms of coatings on steel, and identify methods for overcoming the problems associated with efflorescence. Also, advisory and consultative services based upon laboratory and field tests will be performed.

On the basis of a proposal submitted to the U.S./Spain Advisory Commission for Technological and Scientific Research on September 23, 1977, a cooperative investigation between the Laboratorio Central de Ensayo de Materiales de Construccion del Centro de Estudios y Experimentacion de Obras Pulicas y Urbanismo (Spain) and CBT began in September 1978. The subject of the research was "Factors Affecting the Corrosion of Steel in Prestressed Concrete Structures" and the work was planned to extend over the 5-year period, 1978-1983.

Prestressed concrete is a form of reinforced concrete that makes highly efficient use of concrete and steel but puts particularly severe demands on these materials. The use of prestressed concrete for building and other construction such as bridges and pipelines is important in both the United States and Spain and, in view of its implications for conservation of energy and raw materials, its use must be expected to grow. Although the problems encountered with the performance and durability of prestressed concrete in the two countries appear to be different, there is a common basis of need for technical knowledge about factors affecting the 
performance of prestressed concrete. The purpose of this project is to develop an improved understanding of the factors affecting the corrosion of prestressing steel in concrete and to identify methods for detecting corrosion of prestressing steel while in service.

\section{Short-Term Evaluation of Steel Coatings}

Jonathan W. Martin

(301) 921-3208

Structures and Materials Division

Sponsor: Federal Highway

Administration

\section{Field Adhesion Tester}

James F. Seiler

(301) 921-2909

Structures and Materials Division

Sponsor: Tri-Services Committee

\section{Properties of Single-Ply Roofing Systems}

\section{Robert G. Mathey}

(301) 921-2629

Structures and Materials Division

Sponsor: Tri-Services Committee
The Federal Highway Administration is seeking to reduce the costs of painting steel structures by increasing the length of the painting cycles through the use of improved coating systems. Effective short-term evaluation procedures for evaluating the durability and protective qualities of these coating systems are essential to achieve this goal. Under this project, CBT will evaluate the validity and usefulness of short-term testing used for coatings on steel. Short-term evaluation procedures will be developed for coatings that will provide maximum reproducibility and correlation with service conditions. A users' guide for evaluating and selecting coatings will also be written.

Adhesion is an important performance characteristic of many building materials, e.g., paints, roofing, and wall coverings. But present field methods for adhesion measurement are restricted to spring-loaded devices, which have many problems for obtaining quantitative measurements. Problems stem from variables such as type, bond thickness and cure of adhesive, surface preparation, and rate of loading. In this project, the portable pneumatic adhesion tester developed at CBT will be characterized for repeatability, reproducibility, and suitability for use with different adhesives. Also, the adaptability of the instrument to measure the adhesion characteristics of coatings in the field will be studied.

Under this project, laboratory tests will determine the properties (tensile strength and elongation) of 19 types of single-ply sheet materials at $21^{\circ} \mathrm{C}\left(70^{\circ} \mathrm{F}\right)$ and $-18^{\circ} \mathrm{C}$ $\left(0^{\circ} \mathrm{F}\right)$. Changes in properties due to degradation of the sheet materials will be determined after exposure to accelerated aging, heat aging, ozone, xenon arc, and outdoor weathering. Three types of tests to measure tensile strength and elongation (ASTM D412, D882, and D2523) will be assessed. 
Measurements and Standards for Nuclear Waste Management

Felix Y. Yokel

(301) 921-2648

Structures and Materials Division

Sponsor: Department of Energy
The Interagency Review Group (IRG) on Nuclear Waste Management estimated that there are now 76 million cubic feet of long-lived radioactive nuclear wastes from military and civilian programs stored at various interim sites around the United States. In addition, there are large quantities of uranium-mill tailings, transuranic wastes, and spent fuel discharged from commercial nuclear power reactors. In the meantime, nuclear waste continues to be generated by the military weapons and propulsion programs and by the operation of over 65 nuclear reactors and associated fuel service facilities. The environmentally safe storage and/or disposal of these wastes has aroused profound public concern both domestically and internationally.

A number of alternative methods for handling high-level wastes, which require the greatest technical input for safe management and disposal, have been proposed. The IRG recommended that these wastes be put into a stable form and disposed of by burial in deep geologic sites using a multi-barrier system which includes container, filler, overpack, sleeve, backfill, and the borehole plug. CBT is involved in the study and evaluation of the backfill components of this multi-barrier isolation system.

This project will provide technical and scientific support and consultative services on building materials and systems as required by the Tri-Services. The work will include carrying out laboratory tests and evaluations in the solution of building problems and field investigations. Recommendations will be made on the selection of materials and systems and their application and performance. In the past, problem areas have covered plumbing, masonry, roofing, corrosion, mechanical systems, insulation, materials, and underground piping. 
[Earthqualke Hazaro] Redustion

5จ Reongrton

\section{Earthquake Hazard Reduction}

[ே. Redustion

Earthqua|ke గazar Redugtion

Earthquake Mazard Redustion

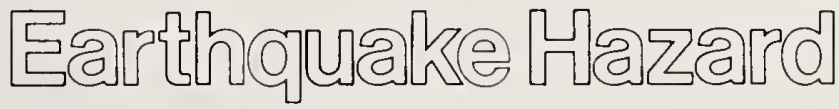
Reduction

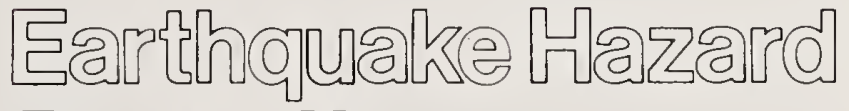
Reduction

[am Reduction 


\section{Seismic Provisions for Buildings}

Edgar V. Leyendecker

(301) 921-3471

Structures and Materials Division

Sponsor: Federal Emergency

Management Agency/National Bureau of Standards
In 1974, the National Science Foundation and the National Bureau of Standards began a program to develop improved seismic design provisions for buildings. As a consequence, the "Tentative Provisions for the Development of Seismic Regulations for Buildings" were developed by the Applied Technology Council in an effort that included a wide range of experts in the actual drafting of the provisions. Because the tentative provisions are quite innovative, questions have been raised about portions of the report. Before undertaking an expensive assessment of the provisions through trial designs, an effort to investigate questions and improve the provisions was started in 1979. This is being done through a series of technical committees that have been assembled to resolve comments on the structural design requirements and design procedures, on the material requirements, on architectural, mechanical, and electrical components and systems, and on the regulatory use of the provisions. CBT is working closely with the Building Seismic Safety Council on each phase of the refinement of the provisions and the development of a plan for assessing the economic impact of the provisions. This review will end with the presentation of the recommended changes to the Building Seismic Safety Council. It is likely that many issues exist that will not be resolved by this activity; some will require the information that will be developed in the conduct of the trial designs and subsequent impact assessment before resolution can be expected.

The Interagency Committee on Seismic Safety in Construction established by the President's Earthquake Hazard Reduction Program will develop improved uniform standards for Federal construction by the end of 1980. CBT is chairing the Subcommittee preparing the draft document. Working through this committee, CBT will coordinate the voluntary efforts of Federal agencies concerned with construction as they conduct a trial implementation of the draft standard. Supplementary studies and review will be conducted to evaluate the draft document in preparation for recommendation of a final standard.

Standards for the design of structures are moving toward a reliability-based limit-states format. Current approaches to the specification of the limit-states for aseismic design have been to use the same limit-states used for gravity and wind loads. However, analysis indicates significantly lower levels of reliability for earthquake than for snow, wind, or live loads when using this approach. Such differences are likely to lead to unsafe or uneconomical standards for aseismic design or to delay the use of reliability-based limit-states approaches for the design of all loads. This project will improve the consistency of reliability-based design of structures through a clear 


\section{Romania Earthquake Rehabilitation}

Randolph Williams

(301) 921.2196

Structures and Materials Division

Sponsor: U.S. Geological Survey

\section{Computer-Controlled Test Facility}

Kyle A. Woodward

(301) $921-2885$

Structures and Materials Division

Sponsor: National Bureau of Standards

\section{Cyclic-Loading of Masonry Building Components}

Kyle A. Woodward

(301) 921-2885

Structures and Materials Division

Sponsor: National Bureau of Standards identification of the design limit-states and the important response parameters.

Following the March 4, 1977, earthquake in Romania, a team of NBS and USGS engineers visited Romania to inspect earthquake damage and identify ways in which U.S. technology could be used to aid in post-earthquake recovery. Specific recommendations were made to the Romanian Government concerning structural rehabilitation, earthquake monitoring, and earthquake engineering. The USGS has requested that CBT provide guidance to select, purchase, and evaluate instrumentation needed for earthquake engineering research. The project included a survey of earthquake engineering laboratories in the United States. A list of earthquake engineering equipment was compiled and submitted to representatives of the Government of Romania for their approval. CBT will now assist USGS with contract documents for the selection, purchase, and acceptance of the instrumentation for earthquake engineering research.

The project will develop a test facility in which building components can be subjected to large loads in three orthogonal directions simultaneously with variable rotational restraint. In addition, CBT will develop the computer software to permit total computer control of specimen loading, data acquisition, and test monitoring. The test facility will be constructed in stages. Each stage will introduce additional complexity into the development and capabilities of the facility. Successive stages will be undertaken only after the facility in preceding stages undergoes trial and actual use.

The process of developing tentative seismic design provisions for both unreinforced and reinforced masonry building components reveals a scarcity of information on its ultimate strength characteristics. Since seismic resistance is based primarily on ultimate strength considerations, the lack of such information for masonry building components is detrimental to its rational design in buildings subject to seismic loadings. Under this project, experimental tests will provide vitally needed information not now available that will be a resource to many investigators and will serve as the basis for development of mathematical models. A number of failure modes will be examined to identify the characteristics of each and the significant parameters affecting the different failure modes. Analytical expressions for predicting failure as a function of the key parameters will be developed. 


\section{Cyclic-Strain Approach to the Determination of Liquefaction Potential of Level Sandy Sites}

Riley M. Chung

(301) 921-2648

Structures and Materials Division

Sponsor: National Bureau of Standards

Improving the Standard Penetration Test as a Measure of the Liquefaction Potential of Sands

William D. Kovacs

(301) 921-2885

Structures and Materials Division

Sponsor: Nuclear Regulatory Commission
Relative density is currently used as the single most important parameter in preparing laboratory specimens of sand to model in-situ conditions. Research now indicates that many other characteristics of the soil are important, such as the manner of deposition, history of preconsolidation, and history of vibration. These are collectively referred to as the soil "fabric". At present, two methods are used to predict liquefaction potential of sites. In the first method, Standard Penetration Test results from the site are compared with those from sites that liquefied in the past. In the second method, reconstituted samples are subjected to cyclic stress in the laboratory, using Standard Penetration Test results to determine relative density in the field. In this project, a relationship between cyclic strain and pore water pressure buildup is established. Anticipated cyclic strain, in turn, can be estimated on the basis of the shear modulus of the deposit which can be approximately determined from shear wave propagation velocities.

The Standard Penetration Test (SPT) ASTM D 1586-67 is a well known and popular in-situ field test used in foundation design and in the determination of liquefaction potential of saturated sands. Although the SPT has enjoyed wide use, there now exist many known and recognized details of the test procedure that remain uncontrolled, thereby contributing to wide scatter of test results. The U.S. Nuclear Regulatory Commission is greatly concerned about liquefaction potential of proposed power plant sites and recognizes that energy reaching the sampler is the key to reproducible field test results. Under this project, CBT will test various methods and develop procedures for measuring the energy during the performance of the SPT and evaluate available SPT data on liquefaction. 


\section{Buolding Safferty}

Budding Safefty

Building Safety

Budnding Sarfety

Buidong Sarefty

Bualding Sarefy

Bualding Safefin

Bunding Saffety

Bundong Safefty

Budding Safery

Budding Safferty

Budling Sâfety

Bundong Sarfery

Bualding Safelty 


\section{Construction Load Evaluation}

H. S. Lew

(301) $921-2647$

Structures and Materials Division

Sponsor: National Bureau of Standards

\section{Excavation Safety}

Felix Y. Yokel

(301) 921-2648

Structures and Materials Division

Sponsor: National Institute for Occupational Safety and Health

\section{Effectiveness Evaluation of Symbol Use}

Belinda L. Collins

(301) 921-2237

Environmental Design Research Division

Sponsor: National Bureau of Standards
Design-load requirements in existing standards for falsework are not adequate and are often identified as one of the major contributing factors in construction failures. This is due primarily to a lack of documented construction-load data. In concrete construction using specially instrumented shores and time-lapse photography, construction loads in building construction will be measured under this project. Treating magnitude and frequency of field data as random variables, a mathematical model for construction loads will be developed that can be used for reliability analysis of evolving structures during construction. The model also will be used for simulation analysis of multi-story construction process.

Collapses of trenches and excavations in the United States cause annually several hundred fatalities and many more injuries. Most of the fatalities occur in shallowbraced utility trenches (about $10 \mathrm{ft}$ deep). Current OSHA provisions for sloping and shoring of trenches are not effective (their promulgation in 1971 did not reduce the accident rate) and are also difficult to interpret, resulting in costly disputes and litigation between contractors and the Government. CBT studied the excavation problem and prepared a series of reports on recommended trenching practice. These recommendations will be used to develop a draft of a new trenching standard, which in turn will be thoroughly reviewed by the membership of the Association of Soil and Foundation Engineers, the Associated General Contractors of America, the National Utility Contractors Association, and the AFL-CIO, and then discussed in several regional workshops sponsored by these organizations. The Industries' comments, together with the original draft, will be used to prepare a final recommendation for a standard for excavation trenching and shoring that can be used by OSHA as a basis for new regulations and can be submitted to ANSI Committee A 10.12 for possible adoption as a voluntary consensus standard.

Despite the widespread use of symbols for safety applications, many components of their effectiveness have not been evaluated systematically or parametrically. Issues such as size, figure-ground relationships, visual clutter, color, and placement all affect the overall effectiveness of symbols. National and international codes are based upon promises about each of these as-yetuntested factors. As a result, there is a need for a parametric evaluation of the components of symbols, which affect their effectiveness. This project will thus provide guidelines to the development of codes and standards for more effective symbols. 


\section{Effectiveness of Safety Symbols in the Workplace}

Belinda L. Collins

(301) 921-2237

Structures and Materials Division

Sponsor: National Bureau of Standards

\section{Building Circulation Evaluation System: Phase I}

George Turner

(301) 921-2102

Environmental Design Research Division

Sponsor: National Bureau of Standards
The state-of-the-art literature on methods of evaluation has been reviewed and documented. The need for symbols in the workplace has been determined by assessing the demand for and use of existing symbols and hazard warning signs. A research program was developed based upon the review of methods for evaluation and existing symbol-use practices. Following the pilot experiment, a testing program has been implemented in which safety symbols are evaluated for their effectiveness. The testing program now in progress includes evaluation of symbols for a variety of worker populations. Recommendations will be made concerning the effectiveness of various sets of safety symbols proposed for use in the workplace.

Building design, research, and regulation intended to improve user circulation has historically been accomplished, for the most part, on a piecemeal basis taking a single circulation element at a time. This approach has been successful at redressing immediate problems in buildings and sites, but fails to consider the building and its site as a total system characterized by progressive interaction between the building users, performing circulation-related tasks, and the building environment. Likewise, absolute stoppage of the user has been the principal concern of public and governmental regulators to date, yet stoppage can and does occur when a number of lesser restrictions and inconveniences are cumulatively encountered. Stoppage is also the secondary result of a user personal injury unrelated to the physical system of the building or facility.

Under this project, CBT will develop a preliminary set of important scenarios of user performance loss in buildings; draw upon candidate user groups analyses of the scenarios for comprehensiveness and level of importance; develop a computer analysis capability to interrogate critical scenarios for parameters such as performance loss type, event, activity, user type and impediment; and analyze the scenario interrogations; then identify the array of conditions that result in the greatest performance loss to the greatest number of building users, leading to the largest aggregate performance loss to the population.

This work will provide the rationale for a detailed, longterm research plan for use in developing future circulation standards, replacing the pure-specification approach now used. It represents the next generation of evaluation of building circulation and provides the method for regulators and building designers to converse on performance-based standards and on the effectiveness level at which a full facility operates. Cost studies can ultimately be coupled with the system to determine the cost-optimal approach for candidate facilities designs. 
Modeling Occupant Circulation Systems

Fred I. Stahl

(301) 921-3595

Environmental Design Research Division

Sponsor: National Bureau of Standards

The Use of Hazard Pictorials/Symbols in Mines

Belinda L. Collins

(301) 921.2237

Environmental Design Research Division

Sponsor: U.S. Bureau of Mines
The design of occupant circulation systems for buildings is often complex and multifaceted, involving both environmental and human behavioral factors. Circulation problems may occur not only during a building's normal use, but whenever such emergencies as fires arise as well. It is often difficult to predict building performance with respect to circulation safety, since the needed tools do not now exist. The BFIRES simulation program, developed earlier under this project, is a new tool intended to aid in the prediction of emergency egress response during fires. This is an example of the type of occupant circulation model that could usefully be applied to building design and regulation. This year, the performance of simulated building occupants during "fires" run under BFIRES shall be evaluated with respect to data documenting historical fires. Dr. John Bryan, Chairman of the Department of Fire Protection Engineering at the University of Maryland, has conducted detailed post-incident investigations of more than 30 residential and institutional fires. Prepared under an NBS grant, his reports and data are readily available. In many cases, his data describing occupant behavioral patterns are at a level appropriate for comparison with patterns generated during BFIRES simulations. In the proposed investigation, a sample of historical fires documented by Dr. Bryan will be simulated using BFIRES, and the human behavioral scenarios from both the "real world" and simulated events will be compared. This will permit, for the first time, the evaluation of BFIRES-produced behavior patterns at a level finer than simple event outcomes.

Symbols used to provide emergency and safety information in buildings and mining environments including mills must communicate effectively under a wide range of visual conditions, which can include poor illumination, dust, and glare. Meaningless, confusing, contradictory, and ineffective symbols are in use because selection of symbols is typically made without sound technical data on their effectiveness. Evaluation of safety symbol signs is particularly critical since these are used to warn of potential danger and convey critical safety information. There is need to assess the effectiveness of hazard pictorials in mining environments to provide research-based data on the performance of selected symbol signs.

CBT research includes collection and review of existing symbols and sign systems, and compilation of all applicable standards. The need for mines and mills safety symbols will be documented and categorized. Laboratory and field-based research methods will be developed and applied with the goal of determining experimentally the characteristics of effective symbols under normal and reduced visibility. The effectiveness of suggested mine 
safety signs will be experimentally assessed under the appropriate viewing conditions with a selected sample of mine workers. The results from this research will provide the experimental base for symbols and hazard warnings in mining environments. The research results will be transmitted to the standards community for their implementation.

\section{Technical Support for Correctional Facilities Design Standards}

Robert L. Tibbott

(301) $921-2670$

Environmental Design Research Division

Sponsor: Law Enforcement and Assistance Agency (LEAA)
Since 1975, LEAA has been supporting programs to develop standards for correctional facilities and services through grants to the American Correctional Association. The standards were developed by the American Correctional Association through a consensus procedure. Generally, the American Correctional Association is responsible for the development and revisions of the standards while the Commission on Accreditation for Corrections is responsible for the accreditation process using these standards. The current standards contain requirements for light levels, air circulation, and noise levels. However, there are no test procedures in the document for measuring light levels, air circulation, or noise levels. Obviously, these requirements would be more definitive and easier to understand if there were test procedures developed to measure them. This work will consist of a thorough review of available standards and supporting documentation to suggest measurement procedures appropriate for correctional facilities. In the case of noise, since no available data or standards are thought to be appropriate, a research plan will be prepared to develop the necessary information. The work is being performed as part of the consensus standards procedure for the American Correctional Association. 



\section{Emergy \\ conservatนก in Buindings \\ Energy \\ Conservation \\ in Buildings}

Energy

Conservanton

in Buildinges

Energy

Conservation

in Buildings

Energy

conservanton

ůn Buildings

Energy

conservarton

in Buildings 


\section{Building Energy Performance Criteria}

Jim L. Heldenbrand

(301) 921-2177

Building Thermal Performance Division

Sponsor: Department of Energy

\section{Integrated Energy Systems}

Clinton W. Phillips

(301) $921-2537$

Building Equipment Division

Sponsor: Department of Energy

\section{Energy Analysis Procedures}

Tamami Kusuda

(301) 921-3501

Building Thermal Performance Division

Sponsor: Department of Energy
Recent Federal initiatives to reduce energy use at the design stage of new buldings have pushed toward the expansion of performance criteria to include the whole building level. Preliminary research for the development of such criteria was based largely on statistical analysis of calculated building design energy requirements without specific regard to the performance of the building components themselves. A Life-Cycle Costing (LCC) approach to development of the criteria has been recommended by CBT and preliminary work by Battelle N.W. Labs and Lawrence Berkeley Lab for DoE has applied the LCC approach to envelopes of residential buildings. CBT will be developing illustrative building energy performance criteria that cover both the envelope and heating and cooling equipment for single-family dwellings. This project will produce a method for integrating component performance criteria that represent user needs (including functional and safety needs) into economics-based whole-building criteria.

Implementation of energy-saving integrated energy systems for buildings, groups of buildings, building complexes, communities, and cities requires extensive technical information development and exchange. To augment the basic technology of integrated energy systems, such as district heating/cooling, total energy, and cogeneration, solutions for economic, institutional, and regulatory constraints are needed. Strong national and international technology exchange, including technical design, operations measurement, and evaluation are necessary, and will be fostered under this project.

The success of the Building Energy Performance Standard hinges on the availability of accurate, yet easy to use, energy analysis procedures. Although DoE has identified the DOE-2 program as the standard benchmark energy analysis procedure, this particular program is not suitable for use by practicing engineers and energy officials because of its complexity and its requirement for large computers. This project will provide the criteria for certifying commercial and useable energy analysis procedures, which would result in an annual energy consumption estimate compatible with that produced by DOE-2. 


\section{Energy Analysis of the Norris Cotton Building}

W. B. May

(301) 921-3633

Building Thermal Performance Division

Sponsor: Department of Energy

\section{Energy Analysis of Control Strategies}

Walter Parken

(301) 921-3774

Building Equipment Division

Sponsor: Department of Energy
The Norris Cotton Federal Building, Manchester, NH, was designed to demonstrate and test the feasibility of a number of energy-saving concepts. For this reason, it uses a variety of equipment such as heat pumps, modular boilers, an engine/generator with waste heat recovery, solar collectors, liquid thermal storage tanks, and special lighting systems. Exterior walls are of heavy masonry construction with an outer insulating layer to create a "thermal flywheel" thereby reducing peak heating and cooling loads. The windows are double-glazed and occupy a relatively small fraction of the exterior facade. Fin-like granite panels surround the windows and are fixed in a position that reflect in sunlight during winter, block out sunlight in summer, and break up strong winds that tend to increase heat loss through the windows. Of the building's seven floors, no two are the same. Each one has some variation in its mechanical equipment, lighting, and/or window arrangement. The purpose of the project is to assess the effectiveness of the several different energy saving concepts.

A computerized building control system was installed and used as a data acquisition system to sense critical temperatures, fluid flows, and electrical power throughout the building and record this information on magnetic tape. These tapes were sent to CBT for analysis. The output will be a breakdown of the buildings energy use. Final analysis and documentation will be completed this year.

Under this project, the computer program BLAST-2 will be used to evaluate strategies for a variety of different HVAC systems, building types, and climatic regions. Typical strategies to be studied include: dry-bulb economizer cycle, enthalpy economizer cycle, hot and cold deck temperature reset, floating space conditions, scheduled start/stop, etc. In addition, work will begin to modify either NBSLD or the building-loads portion of BLAST-2 to make it into a dynamic simulation model capable of predicting building loads and space temperatures on a minute-by-minute basis. Experimental testing to verify this new dynamic simulation model will begin using a mobile home in an NBS environmental test chamber. A CBT report will be published documenting the energy saving potential of the most commonly employed control strategies in a variety of different applications. 


\section{Thermostat Test Standard}

James Y. Kao

(301) 921.3844

Building Equipment Division

Sponsor: Department of Energy

\section{CBT Controls Laboratory}

George E. Kelly

(301) 921.3839

Building Equipment Division

Sponsor: National Bureau of Standards
The present standard used for testing analog thermostats is issued by the National Electrical Manufacturers Association (NEMA). This standard assumes a certain fixed relationship between the heating/cooling plant performance, the building characteristics, and weather variations. The results from using the NEMA test standard may be used for comparing thermostats under this set of constraints, but they cannot be used to accurately predict the inservice performance of a thermostat. With the advent of new, inexpensive microprocessors, there has been a rapid increase in the sale of microprocessor-based thermostats. Although the design of these thermostats is still evolving, there is an urgent need to determine their general operating characteristics. To do this it will be necessary to determine if the test procedures for analog thermostats can be adapted to microprocessor-based thermostats or if new test procedures must be developed.

Better products will be a direct result of an upgraded industry-wide test procedure. The thermostats covered under the test procedure will include not only the present mechanical thermostats for which the NEMA standard was developed, but also the new thermostats that employ electronics and microprocessors. Energy savings obtained through conservation measures will be more clearly predictable and the energy savings claimed by thermostat manufacturers will be easier to verify. This will discourage false advertisement of energy savings and help protect the consumer.

About a fourth of the total U.S. energy consumption is expended in heating, ventilating and air conditioning residential, commercial, and institutional buildings. Each year a considerable amount of manpower and money goes into maintaining the equipment and systems that service these buildings. Fire prevention and alarm systems are usually completely separate and rarely make use of the advanced technologies currently under development for energy control systems. Fire control in small buildings is usually completely separate and independent of all other services. Computer-based energy management systems are so complex that most building designers are afraid of them. This list of problem areas indicate the desperate need of the building community for information on how to design, control, and integrate the various services provided in today's buildings. Guidelines and specifications are needed to fill these information gaps and to provide how-to-do-it manuals for building designers, owners, and operators. Such information would greatly improve the reliability of building systems and controls, reduce maintenance requirements, and provide better services at lower costs. 
To help solve these problems and to provide the "handson" experience necessary to carry out research on building controls and computer-based building management systems, CBT will establish a laboratory for performing fundamental and applied research on building systems and controls. The creation of such a laboratory will provide a means of carrying out basic research on building controls, including control dynamics and the application of adaptive optimization techniques.

\section{EMCS Algorithms}

\author{
Alexander David \\ (301) 921.3839 \\ Building Equipment Division
}

Sponsor: Department of Energy and Department of Defense

$+$
Most of the small companies entering the EMCS market do not have the experience or technical expertise to develop sophisticated algorithms. As a result, a building owner or manager who purchases an EMCS system from a small company is often stuck with an energy management system that either doesn't work or works inefficiently. In this study, algorithms for both on-line control and energy conservation will be developed by CBT personnel and contractors having extensive experience in EMCS. The existence of these nonproprietary algorithms will contribute towards providing a minimum level of performance of energy management and control systems. A report will be completed in FY81 containing the logic flow diagrams for at least two EMCS algorithms that relate either to energy conservation or on-line control.

To provide Navy personnel with information that will assist them in evaluating the performance of their EMCS systems, CBT will hold a workshop on sensors and measurement instrumentation, their characteristics, and how to calibrate them under both laboratory and field conditions. The workshop will be held in 1981 .

Under this project, studies of the sensitivity of building energy requirements to various types of sensors will be performed using a suitable energy program (BLAST-2, DOE-2, etc.) and the energy consumption of a typical building/system using specific weather data will be calculated. These studies will be identical in approach to those conducted in FY80, which included analysis of indoor and outdoor control of economizer cycle, errors in cooling-coil discharge temperature, and chiller discharge temperature as affected by uncertainties in drybulb temperature and humidity. The second phase will be to develop the performance requirements of these sensors, including factors such as stability, response, accuracy, maintenance, and environmental conditions. CBT will produce guidelines for the selection of EMCS sensors, which will be offered to the Interagency 
Working Group organized by Tri-Services for use in the EMCS Guide Specification, and to private architectural/engineering offices and Federal agencies.

Dynamic Performance of HVAC Systems and Controls

\author{
George Kelly \\ (301) 921-3839 \\ Building Equipment Division
}

Sponsor: Department of Energy

\section{Laboratory Tests for Thermographic Standards}

Richard A. Grot

(301) $921-3470$

Building Equipment Division

Sponsor: Department of Energy

\section{Air Infiltration in Large Buildings}

Richard A. Grot

(301) 921-3470

Building Equipment Division

Sponsor: Department of Energy
This project will produce a simulation model for evaluating the dynamic performance of control systems used in the heating and cooling of buildings. A CBT report will be produced describing this model and analyzing some of the control dynamics likely to occur in building HVAC systems. The results of this research will also be published in technical journals and conference proceedings. The information will result in guidelines for optimizing building operation, which will be incorporated in the ASHRAE Handbooks.

Under this project, ground-based infrared imaging systems and inspection techniques will be evaluated for their application to building heat-loss detection. The ? adequacy of various standards for thermographic inspections, such as the ASHRAE standard, the draft ASTM standard, and the ISO standard, will be assessed in five cities. The thermographic inspectors checking the homes in these cities will be required to perform their inspections of the building according to one particular standard, chosen from the above. CBT will monitor these inspections to determine if the standards were followed and compare the results of the surveys with CBT inspections of the buildings. The evaluation of the equipment specifications for spatial resolution, thermal resolution, noise characteristics, geometrical response, signal transfer function, and summary measures will be conducted in the laboratory on candidate infrared sensors used for building inspections. The laboratory evaluations will be performed in CBT environmental chambers to assess the effect of both object temperature and ambient temperature on the equipment parameters. The results of these laboratory tests will be correlated with observed building defects to determine the importance of each equipment parameter on the conditions under which the equipment is used for heat-loss detection.

Reduction of outside air is one of the strategies proposed to save energy in the heating and cooling of buildings. The primary product of this project will be a data base of air exchange rates in high-rise buildings based on experimental analysis of the air leakage behavior of one or more high-rise buildings. Papers and presentations will be given at meetings of organizations such as the International Energy Agency, ASHRAE, and appropriate committees on air infiltration. Results of this research will be made available to engineers having responsibility for the design, maintenance, and operation 
of energy efficient buildings, as well as Government agencies concerned with buildings. Data gathered from the Collins Building, in Scotland, will be submitted to Annex $\mathrm{V}$ of the International Energy Agency for use in the testing of building-energy-load models. A Federal Workshop on Air Infiltration in Large Buildings is scheduled for September 1981.

\section{Evaluating the Performance of Heat Pumps}

David A. Didion

(301) 921.2994

Building Thermal and Service Systems Division

Sponsor: Department of Energy

\section{Heat Pump and Air Conditioner Test Procedures}
David Didion
(301) 921-2994

Building Equipment Division

Sponsor: Department of Energy
The first objective of this study is to determine the significance of the startup, shutdown dynamics on the energy performance of an absorption air conditioner of residential size. If the dynamics prove significant (as is anticipated), the second objective will be to transform the steady-state evaluation standard (under draft review) into one that will include these dynamic effects. The first product of this study will be a CBT report that includes the test results and an analysis of the significance of the dynamic effects on seasonal performance and whether the transients follow a path that is amenable to a timeconstant simulation. The second product will be a recommended standard test and evaluation procedure for residential absorption heat pumps in the cooling mode.

This project will develop a procedure that will enable manufacturers to use the laboratory data from one indoor/outdoor coil combination to predict the performance likely to result from using other indoor coils with the outdoor section tested. The effort involves: using the CBT steady-state model of the heat pump to confirm theoretically whether empirical results are reasonable, and (2) laboratory measurements of a 3-piece heat pump with various coil combinations. Additional test procedure simplification work will be conducted by extending this dual theoretical and laboratory study to include the effects that different basic design features (thermal expansion valve, capillary tube, fixed orifice) have on the part-load and seasonal performance of this equipment. This work will lead to a subcategorization of this equipment in a manner that will allow for the performance to be more predictable on less empirical information, thus lightening the test burden. A parallel CBT-sponsored program of heat-pump model development is expected to make available a new dynamic performance model sometime this fiscal year to support this effort. 
Furnace and Boiler Test Procedures

David Didion

(301) 921-2994

Building Equipment Division

Sponsor: Department of Energy

Underground Heat Distribution Systems

Tamami Kusuda

(301) 921-3501

Building Thermal Performance Division

Sponsor: Department of Defense and TriServices Committee

\section{Daylighting Prediction}

Tamami Kusuda

(301) 921-3501

Building Thermal Performance Division

Sponsor: National Bureau of Standards
To assist DoE in refining the test procedure to account for jacket losses, the dual theoretical/laboratory study started in FY80 will be continued. This effort has caused CBT to develop a computer model that simulates the effect of furnace and boiler location on seasonal performance and annual operating cost. It has been designed to cover installation in indoor living areas, indoor closets, outdoor closets, outside and in "unheated" basements. The model is being verified by conducting experimental studies on a mobile home located in a large environmental chamber at CBT. The chamber's ability to simulate any temperature/humidity profile in the United States, in effect, provides a field test verification under tightly controlled and known conditions. The furnace unit is located with the mobile home and is thermally isolated to varying degrees from the major living space of the home to simulate the different installations mentioned above. The results of this work will lead to a modification factor for adjusting the rating of the furnace's laboratory measured value for installation location. (Currently 100 percent credit is given for jacket losses.)

Although underground heat distribution systems are often considered in the energy-conservation plans of communities, many of the existing systems have been failing due to ground water seeping into the system and the rupture of the carrier pipes. Under this project, CBT has constructed a conduit boiling test apparatus, conducted the boiling tests on three different calcium silicate insulation systems, and prepared three technical reports. The Tri-Services engineers are interested in how the non-calcium silicate-type insulation can be evaluated in the conduit boiling test as well.

The CBT Daylighting Laboratory has been instrumented with a sophisticated microprocessor-based data acquisition and control system with an extensive array of indoor and outdoor radiation, illumination, and luminance sensors, enabling these parameters to be continuously monitored for each compass orientation and for an unobstructed horizontal surface. The illumination and thermal characteristics of skylights, innovative fenestration designs, and window management systems will be measured and evaluated for their impact on building energy performance. The data will be used to develop and validate the generalized daylight calculation routine for incorporation in building energy analysis programs. 


\section{Radon Transport in Building Materials}

Lawrence I. Knab

(301) $921-3120$

Structures and Materials Division

Sponsor: Environmental Protection Agency
The potential health hazards of radiation exposure to the general public due to radon in buildings has, in the past few years, received increasing attention. One of the most poorly understood and critically needed areas of research concerns the sources of indoor radon and the relation to radon transport through and exhalation from building materials. An understanding of the transport-exhalation mechanism is necessary to predict the sources of radon and routes of entry into buildings. What is needed is a phenomenological basis or models that can be used to characterize building materials as sources of radon, and to characterize the mechanism of radon transport through building materials. In this project, the current state of knowledge of radon transport or emanation from key building materials will be critically assessed. Laboratory diffusion and transport measurements will be conducted as needed. The intrinsic properties of selected building materials (which contain radium) as well as external physical parameters that influence the emanation of radon from them will be investigated. Mathematical models of coupled transport and convective mass transport of a gas through a plane will be applied to the estimation of radon flux through and out of building materials that constitute a source of radon. 

Bufilong Thernal Envelope Systems and Insulathing Maใeria|s

\section{Building Thermal Envelope Systems and Insulating Materials}

Buifling Therrnal Envelope Systeñs and Insulanting

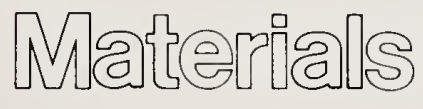

Butloing thernal Envelope systeñs and Insulanting Materia|s

Builling Therma Envelope Systeñs anol trasufanting Materนโด 


\section{Thermal Conductivity Apparatus (1- meter Guarded-Hot-Plate)}

Mahn Hee Hahn

(301) 921.2486

Building Thermal Performance Division

Sponsor: National Bureau of Standards

Thick Insulation Test Series

Chock I. Siu

(301) 921-3536

Building Thermal Performance Division

Sponsor: National Bureau of Standards

\section{Thermal Insulation Analysis}

Brian G. Rennex

(301) $921-2486$

Building Thermal Performance Division

Sponsor: National Bureau of Standards

\section{Calibrated Hot Box Construction}

Douglas M. Burch

(301) $921-3620$

Building Thermal Performance Division

Sponsor: Department of Energy
Increasing national interest in energy conservation encourages the use of thick insulation-sometimes as much as $300 \mathrm{~mm}$ (12 in) or more. The existing CBT apparatus is designed for accurate thermal-conductivity measurements of insulating material specimens up to 50 $\mathrm{mm}$ thickness. An apparatus capable of precise measurements of thick insulation is needed to provide a calibration base for industry and for independent testing laboratories. This project will result in construction and calibration of a $1000 \mathrm{~mm}$ diameter line-heat-source guarded-hot-plate apparatus for thermal conductivity measurements on materials up to $350 \mathrm{~mm}$ thick.

A series of tests is being made on low-density and highdensity fiberglass insulation using the $200 \mathrm{~mm}$ guardedhot-plate, the $300 \mathrm{~mm}$ guarded-hotplate, and the new $1000 \mathrm{~mm}$ line-heat-source guarded-hot-plate-thick insulation apparatus. The data from this test series will be used to validate theoretical models and to establish the $1000 \mathrm{~mm}$ tester as a suitable apparatus for characterizing Standard Reference Material (SRM) and for measuring thick specimens. In conjunction with this work, the ability to produce calibrated transfer specimens will be established. This work will also eliminate much of the present uncertainty about the effective thermal conductivity of thick, low-density materials.

Under this project, a base will be established for a multiyear approach to investigations into steady-state and dynamic characteristics of heat, air, and moisture transmission in materials, composites, and buildingenvelope systems. Initial emphasis will be given to a detailed plan to analyze and report on the performance of the new $1000 \mathrm{~mm}$ line-heat-source guarded-hot-plate and to derive and validate formulas and analytical models for thick, low-density insulation. Data being supplied from the CBT thick insulation test series research will be used in this analysis and in the production of reports and papers for publication.

The calibrated hot box will be put into service using a test-specimen wall constructed of material selected for the ASTM C16.30 round-robin for wall testers. Tests will be run with a pre-scheduled variation in temperature, humidity, and pressure parameters to encompass a broad spectrum of environmental conditions. Test results will be used to validate mathematical models developed to establish calibration coefficients and correlate with those of other round-robin participants. 


\section{Calibrated Specimen Round-Robin Tests}

Frank J. Powell

(301) 921-3275

Building Thermal Performance Division

Sponsor: Department of Energy

\section{Multi-Room Thermal Modeling}

Tamami Kusuda

(301) 921-3501

Building Thermal Performance Division

Sponsor: National Bureau of Standards

\section{Installation Criteria for Building Retrofit}

Heinz R. Trechsel

(301) $921-2627$

Environmental Design Research Division

Sponsor: Department of Energy

\section{Field Measurements of Building Thermal Mass}

Douglas M. Burch

(301) 921.3620

Building Thermal Performance Division

Sponsor: Department of Housing and Urban Development
This project will develop a round-robin test regime for a test-specimen wall constructed of material selected for the ASTM C16.30 standard. This work will advance the state-of-the-art of testing the performance of insulating materials and wall elements.
Under this project, CBT will conduct a joint program with CAM to study intra-room air convection by a comprehensive fluid-dynamic simulation model. The model will then be extended to a two-room problem to determine the interroom air-leakage coefficient. CBT also will examine the adequacy of the current algorithms used by computer programs to model the interaction between rooms in a building by conduction heat transfer and interroom air transfer against an exact solution that was developed at CBT during FY80. A four-room model will be developed on the UNIVAC 1108.

DoE is required to establish standards for installation of energy conservation retrofit measures to be used under the RCS program. Such standards were developed and published in the Federal Register (November 7, 1979, and September 24 and 25, 1980) for most measures. DoE programs are expected to result in the retrofitting of 90 percent of the existing residential and small commercial building stock. It is the purpose of this project to assist DoE in preparing manuals for installers and others involved in implementing RCS.
It is generally accepted that optimum indoor comfort and the largest reduction in the heating and cooling energy requirements are achieved when the bulk of the thermal mass is located on the interior side of wall insulation. However, in most masonry construction across the country, thermal mass is almost always located on the exterior side of wall insulation. The technical findings of this study will permit the development of preliminary guidelines for the effective use of building interior mass for energy conservation and thermal comfort. CBT reports will be prepared covering the effect of wall mass on heating and cooling energy requirements, the experimental validation of DOE-2, and preliminary thermal insulation guidelines for masonry buildings. The results will also be presented as an ASHRAE technical paper. 


\section{Guidelines for Controlling Attic Condensation}

Douglas M. Burch

(301) $921-3620$

Building Thermal Performance Division

Sponsor: Department of Energy

\section{Field Determination of Wire Temperatures}

T. K. Faison

(301) 921-3293

Building Thermal Performance Division

Sponsor: Department of Energy
The objective of this project is to measure ventilation rates for the attic of a test house equipped with different attic ventilation systems. The measured data will be used in conjunction with a validated mathematical model for predicting the moisture-transfer and heat-transfer processes in an attic to develop revised attic ventilation guidelines. Under this project, the Bowman House will be equipped with various attic ventilation systems (i.e., continuous soffit vents, a ridge vent, roof vents, gable vents, turbine vents, etc.). A series of attic ventilation measurements using the SF6 tracer-gas technique will be performed on each of the various attic ventilation configurations covering a wide range of outdoor winter wind speeds. Separate tracer-gas measurements will be carried out to determine the rate of house exfiltration that penetrates from the living space into the attic space.

A test attic was constructed and extensively instrumented in a high-bay environment simulation facility. This test attic will be exposed to steady-state and diurnal outdoor conditions. The critical attic ventilation rate will be experimentally determined and subsequently compared with the corresponding value predicted by the mathematical model. Using these data, and the mathematical model for predicting the required rate of attic ventilation, revised attic ventilation guidelines will be developed as a function of geographic location, ceiling insulation thickness, indoor humidity level, and whether the ceiling has a vapor barrier.

During this year, the remaining Thermal Indicating Flexible Strips (TIFS) used to measure electrical wire temperatures will be retrieved from the participating utilities. The data will be analyzed to determine the maximum temperature which the branch circuit wiring was exposed during the period of evaluation. Branch circuit wires were covered by insulation materials during energy retrofit. The remaining TIFS to be evaluated will have been exposed to summer conditions, whereas the previous temperature indicators provided information for winter and spring. Information will be developed on maximum temperature of the wire, age, and type of insulation. CBT will also continue its participation on the ANSI Ad Hoc Joint Study Group on Problems of Thermal Insulation with Electrical Systems and the Electrical and Electronic Standards Management Board. 
Buidoing Solal" Systems Technology

\section{Building Solar Systems \\ Technology}

Bunding Sola!

Systems

Technollogy

Buolong Solar

Systems

Technology

Buidong Soldar

Systems

Technology

Buidong Solar"

Systems

Technology 


\section{Collector Durability and Reliability Test Program}

David Waksman

(301) 921-3285

Building Economics and Regulatory

Technology Division

Sponsor: Department of Energy
The reliability and long-term performance of solar collectors has not generally been demonstrated. Recent studies have indicated that significant changes in collector performance (greater than 10 percent) can occur as a result of exposure to "no-flow" conditions for 3 to 9 weeks. Various component and materials tests have been proposed to evaluate the reliability/durability of solar collectors. However, these testing procedures have to be experimentally validated. This project is intended to provide a coordinated testing program that will result in establishing validated testing procedures to relate laboratory, accelerated field, simulated operational exposure, and actual field demonstration data for solar collectors used in building heating and cooling applications.

A review of existing and planned testing procedures useful in evaluating the reliability/durability of collector units and their materials will be conducted. Laboratory and outdoor field exposure tests will be performed on solar collectors and their materials. The results of these tests will be correlated and compared with actual in-use performance. Long-term field exposures will be conducted at a number of different sites to evaluate climatic effects. Test specimens representative of various collector types are being used. NBS Technical Note 1136 published in January 1981 describes the overall test program plan.

While numerous standard tests have been developed for coatings in building construction, the performance requirements involved in solar systems are quite different. For example, temperatures on the absorptive surface may reach $250^{\circ} \mathrm{C}$ or greater, but standard test methods for coatings seldom involve temperatures as high as $100^{\circ} \mathrm{C}$. The purpose of this project is to prepare such draft standards, which will be based upon results of laboratory and field studies and will be submitted to the ASTM Committee E44 for consideration as consensus standards. The research findings will ensure improved absorptive coatings performance, provide a basis for selecting proper materials, and enhance acceptance of solar systems by making them more reliable.

NBSIR 80-1203, Solar Energy Systems-Standards for Absorber Materials, contains data obtained in the study and proposed draft standards. This report and other publications stemming from the study have aided in the development of ASTM E744-80 and E781-81. Additional studies are being carried out to gain data on degradation from outdoor exposure and to develop mathematical models of the degradation. 


\section{Standards for Solar Cover Plates}

Elizabeth J. Clark

(301) 921-2635

Structures and Materials Division

Sponsor: Department of Energy
Most solar collector designs incorporate a cover plate whose purpose is to transmit solar energy while protecting the inner areas of the collector from the exterior environment and reducing the heat loss. Any loss in the transmittance of solar energy through the cover plate results in a decrease in the efficiency of the entire solar heating and cooling system. The transmittance and other important properties of some cover plate materials are frequently deteriorated by sunlight and the temperatures encountered in solar collectors. Many standard test methods are available to evaluate materials such as glass and plastic. However, the performance requirements for cover plates of solar collectors are not entirely covered by test methods developed for applications other than solar. The purpose of this project is to prepare draft performance standards for cover plate materials used in flat-plate solar collectors. The products of the project, drafts of standard test methods by which cover plates used in solar energy systems may be evaluated, will be submitted to ASTM Committee E44 for consideration as consensus standards.

Technical Note 1132, Solar Energy Systems-Standards for Cover Plates for Flat Plate Solar Collectors, was published. The data and draft standards in this report have provided a technical basis for two ASTM Standards, E765-80 and E782-81 on evaluating solar collector cover plate materials.

Solar transmittance and reflectance are the key attributes required, respectively, of cover-plate and absorbercoating materials for solar collectors. Transmittance and reflectance values are used by collector manufacturers, architects, and researchers in calculating expected thermal efficiency and measuring short-term performance. ASTM E424 is the most commonly used standard method for determining solar energy transmittance/reflectance. It contains two methods of measurement: Method A requires the use of a spectrophotometer in a laboratory, while Method B is performed outdoors. It is difficult to obtain the same results using the two methods. In this project, variables within the test methods will be studied to determine their effect. Data obtained will be used to aid in the revision of E424. 


\section{Thermal Test Methods for Solar Collectors}

John P. Jenkins

(301) 921-3871

Building Equipment Division

Sponsor: Department of Energy

\section{Test and Evaluation of Solar Collectors}

Robert D. Dikkers

(301) 921-3285

Building Economics and Regulatory

Technology Division

Sponsor: Department of Energy

\section{Standards for Nonmetallic Containment Materials}

Elizabeth J. Clark

(301) $921-2635$

Structures and Materials Division

Sponsor: Department of Energy
Standard thermal test methods for solar collectors based largely on CBT-proposed procedures have been adopted by ASHRAE. The objectives of this project are to verify the applicability of these test methods to state-of-the-art solar collectors and to investigate alternative test methods, using the indoor and outdoor test facilities at CBT. When needed, the expertise and facilities of other organizations will be used to supplement the experimental work done at CBT. Recommendations concerning necessary test-method revisions and acceptable alternative test methods will be made to the appropriate ASHRAE special project committees.

The Department of Energy is conducting various technical evaluations and testing programs to develop a data base that can be used to evaluate the performance of solar energy systems and components. Such data are needed to serve as the basis of collector certification programs being undertaken by several states and by industry. A secondary goal of this DoE program is the development of testing procedures that can be used to evaluate the reliability/durability and safety of components such as solar collectors. Current collector test procedures and test results being studied pertain to structural performance, fire testing, thermal cycling, rain penetration, and hail loading. These procedures, when validated, can be submitted as drafts to various consensus standards organizations for consideration under the consensus process.

Materials used to contain, transport, or store fluids in solar energy systems are called containment materials. Plastic containment materials are being used increasingly in solar collectors, solar ponds, tanks containing heated storage liquids, and piping. Numerous field problems have been reported with plastics. These problems stem primarily from the poor thermal and UV stability of some plastic materials. Many standard methods are available to evaluate plastic materials. However, the performance requirements for containment materials in solar systems are not entirely covered by the existing test methods. The purpose of this project is to prepare draft standards for nonmetallic containment materials used in solar systems. Initially, performance criteria, performance attributes, degradation factors, and currently available tests were identified. Tests were then assessed to determine if modifications were necessary to reflect solar conditions in use. Laboratory and field studies are being performed to obtain data needed to prepare testing standards. Draft standards will be submitted to ASTM Committee E44 as possible consensus standards. 


\section{Standards for Rubber Hose and Connections}

Robert D. Stiehler

(301) 921-3180

Structures and Materials Division

Sponsor: Department of Energy

\section{Standards for Phase-Change Storage Materials}

Paul W. Brown

(301) 921-2993

Structures and Materials Division

Sponsor: Department of Energy
Rubber hose is an economical and efficient connector between the solar collectors and manifolds on the supply and return lines of solar energy systems. Rubber hose is sometimes also used at the inlet and outlet of pumps, storage tanks, and other components in the system. The environment and other conditions surrounding solar energy systems necessitate a high-quality hose with a long life, good resistance to ozone and other atmospheric pollutants, and good performance at high and low temperatures. The principal task here is to establish minimum requirements for the hose, based on these tests, to assure satisfactory performance in solar energy systems and to incorporate the requirements into draft standards for consideration by ASTM.

A report, NBSIR 79.1917, Solar Energy SystemsStandards for Rubber Hose, has been published. This report includes a draft standard that has been accepted, with modification, by ASTM as D 3952-80, Standard Specification for Rubber Hose used in Solar Energy Systems. Additional laboratory data are being obtained to include pressurized test conditions in the standard. The approach will consist of identifying performance requirements, important properties related to performance, factors that could affect the performance, and existing tests to measure performance of rubber hoses and connections. Laboratory studies will be performed to determine if materials meet the requirements and to develop procedures, as needed, to measure performance. Based on the laboratory studies, draft standards will be submitted to ASTM Committee D11 for consideration as consensus standards.

Phase-change materials provide energy storage in terms of latent as well as sensible heat. These materials offer significant potential advantages in the volume of storage required and the thermal losses from storage.

Consequently, the use of phase-change materials is increasing as the solar industry searches for more effective storage media. Key problem areas relating to the use of phase-change storage materials involve encapsulation and durability. Examples include rupture of encapsulating materials due to mechanical incompatibility with phase-change materials, thermal or chemical degradation of phase-change and encapsulating materials, and crystallization and segregation of components of phase-change materials as a result of repeated cycling and chemical incompatibility between phase-change and encapsulating materials. Research is being conducted to address these problems through the development of performance standards and accelerated tests to allow assessment of the long-term performance and durability. 


\section{Thermal Energy Storage and Building Codes}

Joseph Greenberg

(301) 921-3147

Building Economics and Regulatory

Technology Division

Sponsor: Department of Energy

\section{Development of Solar Regulatory Provisions}

Joseph Greenberg

(301) 921-3146

Building Economics and Regulatory

Technology Division

Sponsor: Department of Energy

\section{Cement Hydrates for Energy Storage}

Paul W. Brown

(301) 921-2993

Structures and Materials Division

Sponsor: Department of Energy
In this project, all thermal energy storage systems and components will be reviewed and potential hazards to health and safety identifed and discussed with the hardware and system developers. These potential hazards will be assessed in relation to existing code provisions and a determination made regarding the potential acceptance of this equipment by code-enforcement officials. The code changes needed to allow installation of equipment in an unmodified configuration will be identified and a course of action suggested.

To make solar energy a viable and maturing energy source for the nation, the regulatory system must not impede technical development. Under this project, model solar building regulatory provisions will be developed and updated in a consensus mode under the sponsorship of the Council of American Building Officials (CABO) using the ANSI-accredited organization approach. CBT will be active on the consensus committee and the various technical subcommittees to provide technical support during the various phases of the development of these consensus documents. In addition, CBT, together with DoE and HUD, will collaborate in the overall planning for this program and will, from time to time, provide oversight assessments regarding the progress of the program toward meeting its overall goals.

The desired features in an energy storage material are high specific heat, high density, low toxicity, low corrosivity, high latent heat (phase-change), small volume change on transition (phase-change), and low degree of supercooling (phase-change). Consideration of these features makes certain hydrated cement compounds attractive candidates for use as energy storage media. Research is underway to investigate cementitious materials that can effectively store energy, to develop performance and durability data, and to develop criteria for selection and use of these materials. CBT is identifying cement hydrates that may be suitable for energy storage media; determining the reversibility of the hydration of the candidate materials, and evaluating the time at temperature dependence of their hydrationdehydration rates; examining the relationship between temperature and solid-state crystal structure modification, examining the effects of composition within the solid. solution phase on specific heat, latent heat, and crystal structure stability; performing long-term tests under simulated service conditions to evaluate the long-term stability of selected cement hydrates; and developing criteria for the selection and use of cementitious materials for energy storage. 
Reports will be produced summarizing the preliminary assessment of the suitability of cement hydrates for energy storage applications, and on criteria for selection of cementitious materials for energy storage. This work will provide the technical basis for the selection of potentially superior energy storage media.

\section{Solar Energy Program for Housing Systems}

Robert D. Dikkers

(301) 921-3285

Building Economics and Regulatory

Technology Division

Sponsor: Department of Housing and Urban Development

\section{Kinetics of Glycol-Based Antifreeze Degradation}

\author{
Paul W. Brown \\ (301) 921.2993 \\ Structures and Materials Division
}

Sponsor: Department of Energy
Under this project, an interdisciplinary team of CBT staff members has participated in the preparation of intermediate solar standards and performance criteria and is participating in the evaluation of residential demonstration solar system performance. Experience gained from the evaluation of system performance will be fed back into the development of improved criteria. The evaluation process during the demonstration program will involve comparisons of actual with predicted system and component thermal performance, and the evaluation of operational problems (materials degradation, equipment failures, etc.). Proposed revisions to existing HUD intermediate standards and performance criteria documents will be published in FY81 for review and comments.

A potentially major problem that may affect the durability of solar collectors is the lack of information on the rates of degradation of glycol-based antifreeze. This is because the degradation of glycols generates acidic reaction products which cause accelerated collector system corrosion. The ethylene glycol antifreeze solutions used in collectors tend to be those marketed primarily for use in automobiles. For automotive applications, it is biannually. Assuming an auto mileage of 15,000 per year and an average speed of $40 \mathrm{mph}$, then the average time, over a 2 -year period, that an antifreeze solution is at the operating temperature is 750 hours. Assuming that the average collector system operates under about the same temperature conditions as a car and is at an operating temperature for 6 hours per day, the equivalent replacement time would be 125 days or about three times per year. This is probably unacceptable both from the standpoints of convenience and economics. It is, therefore, necessary to obtain further information on the mechanisms and kinetics of glycol degradation under the conditions at which solar collector systems operate so that guidelines for the use of glycol-based fluids can be developed. 


\section{Evaluation of IPC Corrosion Test Methodology}

Paul W. Brown

(301) 921-2993

Structures and Materials Division

Sponsor: Department of Energy

\section{Solar Hot Water System Test Program}

Hunter Fanney

(301) 921-3620

Building Equipment Division

Sponsor: Department of Energy

\section{Passive Solar Data Requirements}

Mark L. McKinstry

(301) 921-3754

Building Thermal Performance Division

Sponsor: Department of Energy
This project will assist in the selection of proper metalfluid pairs as a basis for the design of durable solar collector systems. Currently there are no technical data to ensure the validity of the corrosion test methodology as described in Interim Performance Criteria, NBSIR 761187, November 1976 (IPC). This year CBT will prepare a report to verify and modify, if necessary, its corrosion test method. The project results will ease the selection of proper metal-fluid pairs as a basis for the design of durable solar collector systems. The test results have aided in the development of ASTM E745-80.

Several computer codes are being widely used to predict the thermal performance of solar domestic hot water (SDHW) systems. However, they need to be validated with experimental data to justify their wide use. The primary objective of this project is to conduct controlled experiments on typical state-of-the-art solar domestic water heaters and to determine the extent to which the existing computer programs can accurately predict their performance. A second objective is to investigate methods of testing the systems for the purpose of rating and to support ASHRAE in developing a standard test procedure.

Two documents have been prepared for DoE detailing measurements, analysis, and reporting formats for two levels of passive-solar thermal-performance monitoring. These documents have been reviewed and accepted by coordinating committees and included as technical appendices to a DoE program area plan. A passive solar test building has been designed and constructed. It is located at the NBS Annex. The building will follow standard residential construction practices and incorporate several commonly used passive solar heating techniques. Careful monitoring of the thermal performance of the building and experimentation with new instrumentation and analysis techniques should improve recommendations made to DoE. Visits also will be made to sites in the DoE monitoring program to gain further insight into problems encountered in the field. Extensive thermal modelling of the test building has been performed using a general-purpose finite difference computer program. These models will be validated using the measured data. 


\section{Evaluation of Thermal Comfort in Passive Solar Buildings}

Arthur I. Rubin

(301) 921-2177

Environmental Design Research Division

Sponsor: Department of Energy

\section{Health and Safety Criteria for Passive Solar Systems}

F. Eugene Metz

(301) 921-3285

Building Economics and Regulatory

Technology Division

Sponsor: Department of Energy

\section{Modeling for the Analysis of Thermal Comfort in Passive Solar Buildings}

Stanley T. Liu

(301) 921-3525

Building Thermal Performance Division

Sponsor: Department of Energy

\section{Thermal Test Methods for Passive Components}

William Ducas

(301) 921-3620

Building Thermal Performance Division

Sponsor: Department of Energy
Under this project, the body of scientific research completed over the past 50 years in the area of thermal comfort will be reviewed and the findings applied to determine a method of stating in quantitative terms the degree of thermal comfort expected. Based on the study areas of thermal comfort related to passive buildings needing research will be identified.

This project will evaluate current model codes for provisions that may affect solar installations. Code provisions that may be potential barriers will be identified. The project will also evaluate and critique current passive solar technology including buildings from the Federal Solar Demonstration Program and various research findings for aspects that pose potential health and safety problems. Some of the health and safety topics that may be covered are: fire safety, air quality (radon, asbestos, mold, and mildew), thermal health requirements, and physical hazards (glazing, storage containment, and high temperature/pressure).

Over the past several years, the use of solar energy for the heating and cooling of buildings by means of passive design has received increasing emphasis by the architectural and building community and by DoE. However, the acceptance and rapid growth in the number of passive solar buildings will depend to a large extent on user/consumer comfort in such buildings. The inherent greater fluctuations of indoor air temperature, humidity, and mean radiant temperature require the development of special methods to measure the degree of human comfort in passive solar buildings. An NBS report will be produced documenting the results of the study and the method of quantifying thermal comfort will be published at the completion of this project.

Passive solar components have been classified into generic groupings according to their functional roles and a proposed thermal test procedure will be developed for each grouping. Analytical computer models will be developed for each grouping, representative components have been purchased, and controlled field testing facilities will be designed. Thermal performance testing under both laboratory and field conditions and computer simulation will be performed to assess the ability of the proposed test procedures to provide needed thermal performance data. 
Modeling of Passive Solar Buildings

Tamami Kusuda

(301) 921-3501

Building Thermal Performance Division

Sponsor: Department of Energy

Standards for Passive Solar Materials, Components, and Systems

Robert D. Dikkers

(301) 921-3285

Building Economics and Regulatory

Technology Division

Sponsor: Department of Energy
Suitable elements or algorithms by which accurate heatflow quantities can be determined are not now included in existing programs and must be developed and tested over a wide range of parameters before they can be adapted to user-oriented design tools. Specific problems that will be addressed by this work are: infrared reflective surfaces in the heat-balance calculation; multidimensional heat flow with respect to earth contact systems; and the optimal method for building heat transfer calculations employing multi-spaces (rooms or zones). In this project, algorithms for the slab-on-grade problem will be tested on the UNIVAC 1108 computing system with a simple ranch-house model. Sensitivity of the seasonal energy loss to the ground will be studied with respect to the floor-aspect ratio, distances from the adjacent houses, slab conductance, seasonal temperature profiles, and earth thermal properties.

With the impending widespread commercialization of passive solar technology, standards are urgently needed to measure acceptable levels of technical performance. Such standards need to address not only thermal performance but also health and safety, reliability/durability, serviceability and installation. Mechanisms for the implementation of these standards, e.g., laboratory accreditation and certification procedures also need to be developed. Under this project, staff members of CBT working in the development of standards for solar energy systems will interact with the staff of other organizations involved in various phases of the DoE passive solar energy program (i.e., DOE, LASL, LBL, SERI, the Regional Solar Energy Centers), voluntary consensus standards organizations, and industry.

Changes in optical properties (e.g., transmittance, absorptance, and emittance) and mechanical properties (e.g., tensile strength) have been observed for several cover and absorber materials following environmental exposure. Results obtained to date as part of a solar collector reliability/durability test program at CBT have indicated that exposure to combined temperature and moisture significantly accelerates the degradation of optical properties and that mechanical properties are also influenced by exposure to the ultraviolet portion of the solar spectrum. Determination of the relationships that exist between accelerated laboratory and "real time" outdoor exposure tests requires an understanding of these phenomena on a more fundamental (microscopic or atomistic) basis. Microscopic changes (e.g., bond hydrolysis, defect scattering, and oxidation) of selected materials will be identified and measured. The influence of these microscopic changes on the engineering 


\section{Materials Problem Definition: Solar Industrial Process Heat Applications}

Walter E. Shipp

(301) $921-3285$

Building Economics and Regulatory

Technology Division

Sponsor: Department of Energy

The Industry Impact of Solar Equipment Standards

Carol C. Rawie

(301) 921.3602

Building Thermal Performance Division

Sponsor: Department of Energy properties (e.g., transmittance, absorptance, emittance, tensile strength) of these materials will be investigated. This will involve quantifying the defects and determining their influence using models relating optical properties to phenomena such as surface roughness or particle scattering.

The program objectives of the DoE Solar Industrial Process Heat (IPH) program are to stimulate and demonstrate the use of solar technologies as a replacement for and supplement to fossil fuels now used for industrial processes. The successful achievement of the program objectives will rely heavily upon the identification of materials problems and the development of needed standards to define and measure material performance and durability in IPH solar systems. Based on a field assessment of material problems in operating solar IPH projects, this project will identify the need for new or revised solar materials standards.

In developing solar energy standards and certification programs, it is essential to make sure they do not inadvertently stifle innovation or bias it toward inefficient designs. This could happen, for example, if standards which originally represented the state-of-the-art become outdated, or if standards are unduly prescriptive. It could also happen if certifications and ratings neglect important aspects of performance. This could bias innovation toward improving the measured performance aspects at the expense of the unmeasured attributes. It is also important to be sure that standards which are not specifically concerned with solar energy systems, but have impact on them, do not inadvertently discourage innovation. The purpose of the proposed research is to determine the effect of standards and certifications for solar equipment on development, introduction, and diffusion of new solar technologies, especially active and passive systems for heating and cooling buildings.

Many problems of an economic nature are expected to arise in connection with the planning, design, and use of the Solar in Federal Buildings Program. To ensure the success of the program, CBT economics staff will provide technical assistance to $\mathrm{DoE}$ as necessary.
(301) 921-3602

Building Economics and Regulatory

Technology Division

Sponsor: Department of Energy 


\section{Economics Sessions of the Solar Design Workshops}

Jeanne W. Powell

(301) 921-3602

Building Economics and Regulatory

Technology Division

Sponsor: Department of Energy

\section{Conservation and Solar Energy: An Integrated Economic Evaluation Framework}

Jeanne W. Powell

(301) 921-3602

Building Economics and Regulatory

Technology Division

Sponsor: National Bureau of Standards

\section{Comparison of Selected Solar Economic Evaluation Models}

Jeanne W. Powell

(301) 921-3602

Building Economics and Regulatory

Technology Division

Sponsor: Department of Energy
To accomplish the goals of the Solar Federal Buildings Program, it is necessary that architects, engineers, and project managers in Federal agencies understand the principles of solar design, including economic considerations. To this end, $\mathrm{CBT}$ will revise materials for a visual presentation, and participate in a series of from three to four training workshops on solar energy in Federal buildings.

The nature of the relationship between the energy-related alternatives of a building will be investigated both theoretically and empirically to determine the most promising approach to developing an integrated model. An integrated economic evaluation model will be developed, incorporating as many of the options as possible within the time and funding constraint. The resulting integrated model will contain a comprehensive tax analysis, including tax incentives, for commercial investors.

The model will be tested in selected case studies. In these case studies, the model will be applied to the analysis of representative commercial buildings in selected locations. Economic trade-offs among different combinations of HVAC system and building components will be examined within the framework of the life-cycle cost optimization model. Transient load energy analysis programs and solar simulation programs suitable for analyzing commercial buildings and systems will be employed to develop realistic data for testing and illustrating the model.

Under this project, CBT will survey the most widely used solar evaluation models and determine the approach used in each to evaluate and optimize solar energy system economics. The existing models will include, SOLCOST, BLAST, and DOE-II. The modeling techniques and assumptions used in these programs will be compared. Differences in techniques and assumptions among each program will be assessed. Solar domestic hot water and space heating systems will be evaluated for a selected building in a selected climatological area using each model. A report will be prepared on the differences in economic algorithms, assumptions, and data employed by the different programs and on the results obtained from test problems. These comparisons will indicate differences in the methodology of the major existing models, indicate levels of differences in the results obtained by the various models, and promote the standardization of economic modeling techniques for optimizing solar energy systems. 


\section{Cost-Benefit Studies of Solar Federal Buildings Projects}

\section{Stephen F. Weber}

(301) 921-2308

Building Economics and Regulatory

Technology Division

Sponsor: Department of Energy

\section{Residential Solar Data Center}

Patricia M. Christopher

(301) 921-3285

Building Economics and Regulatory

Technology Division

Sponsor: Department of Housing and Urban Development

\section{Solar Systems User Data Base}

Kent Reed

(301) $921-2640$

Building Economics and Regulatory

Technology Division

Sponsor: Department of Energy
Under this project, CBT will study the cost effectiveness of Federal solar demonstration systems based on reported data. The relative cost-effectiveness of different types of solar demonstration systems will be assessed. Sensitivity analysis and break-even analysis will be performed to determine the conditions necessary for specified percentages of the systems to be cost effective.

The National Program for Solar Heating and Cooling is aimed at helping alleviate a critical shortage in the Nation's available fossil fuel resources by promoting widespread commercialization and accelerated use of solar heating and cooling. The raw (noninstrumental) data that is collected from the HUD residential demonstration program is stored, processed, and transmitted to appropriate users and contractors for additional study, evaluation, and dissemination. The system is currently in operation and feedback from the users has indicated a need for a more complex design. The redesign has involved a familiar set of steps as before: study, document, develop the prototype, test, and modify the design. In 1979, the new design was implemented, new user documentation written, and training sessions given. In FY80, emphasis was placed on developing special reports of summary data to be used for analysis of trends, problem areas, etc. In FY81, the final updating of the data-base files will be accomplished.

Under this project, CBT continues to maintain a data information system to provide technical support for tasks under the Solar Federal Buildings Program (SFBP). This information system will use data formats, computer programs, and ADP procedures previously developed in support of the HUD Residential Solar Heating and Cooling Demonstration Program (SHCDP). Working with DoE, their contractors, and potential users of the data, CBT will continue work to define data needs both for computer reports on a regular basis and interactive access to the data base over a terminal. An automatic spinoff of using existing formats and software would be the merger of residential solar data from the SHCDP with Federal Buildings Program data into one common data base. 


\section{Federal Guide Specifications for Solar Heating and Hot Water Applications}

Joseph Greenberg

(301) 921-3147

Building Economics and Regulatory

Technology Division

Sponsor: Department of Energy

\section{Reliability and Maintainability of Solar Heating and Cooling Systems}

\author{
Joseph Greenberg \\ (301) $921-3147$ \\ Building Economics and Regulatory \\ Technology Division
}

Sponsor: Department of Energy

\section{Performance Criteria for Solar Heating and Cooling Systems in Commercial Buildings}

\author{
F. Eugene Metz \\ (301) 921-3285 \\ Building Economics and Regulatory \\ Technology Division
}

Sponsor: Department of Energy
A collection will be made of the specifications now being used by Federal agencies for the purchase of solar heating and cooling systems. The kinds of systems and components involved in this collection will be categorized and the technical data collected and analyzed. These data, augmented by recent solar research findings, will be used to develop a model set of guide specifications. Drafts of these specifications will be subjected to review by selected technical representatives of designers, manufacturers, and Federal agencies. The project will be carried out in cooperation with the Federal Construction Council.

CBT will participate, as a member of the Reliability and Maintainability Status Assessment Team being established by DoE, in the planning, data gathering and assessment of information. CBT will identify all residential data sources, collect the available data, and structure these data in conformation with established data models. In the end, this program will help the solar industry in reducing reliability concerns, improve coordination of current programs related to these activities, and identify standards that may improve performance of solar heating and cooling systems.

An interdisciplinary team, organized from CBT staff members and with the assistance of an outside contractor, participated in the preparation of draft standards and performance criteria and is participating in the evaluation of demonstration system performance. Experience gained from the evaluation of system performance will be fedback into the development of improved criteria. During FY81, CBT staff will assess review comments resulting from a request for public comment in the Federal Register for the proposed document NBSIR 80-2095, Performance Criteria for Solar Heating and Cooling Systems in Residential Buildings. Comments also will be solicited from industry, professionals, standards organizations, and other Federal agencies. The response to these comments should provide significant material that can be used in the updating of a document for commercial buildings. 
Technical Assessment of Buildings Being Considered for Solar Retrofit

James H. Pielert

(301) 921-3146

Building Economics and Regulatory

Technology Division

Sponsor: Department of Energy

Thermal Performance Data Requirements and Evaluation Procedures

Kent Reed

(301) 921-2640

Building Equipment Division

Sponsor: Department of Energy

\section{Solar Utilization in Cities and Towns}

Richard Crenshaw

(301) 921-2627

Environmental Design Research Division

Sponsor: Department of Energy
Those involved with solar retrofit of buildings face a lack of technical information on assessing the condition of affected building systems (structure, electrical, plumbing, and mechanical). A methodology and related technical data for assessing the impact of solar modifications will be developed under this project. The report will provide a basis for those involved with making technical rehabilitation decisions including designers, Government officials, building officials, etc. This project will be coordinated with a proposed standardization activity by the American Society of Civil Engineers, which is developing a standard on condition assessment of existing buildings.

In FY76, CBT worked with ERDA (now part of DoE) and a Performance Evaluation Committee established by ERDA to develop thermal data requirements and performance evaluation procedures for the National Solar Heating and Cooling Demonstration Program. These requirements and evaluation procedures were published in NBSIR 76-1137, August 1976. Considerable experience has been gained over the past 4 years in using the procedures in this report to evaluate systems in the national solar demonstration program. A number of the recommended techniques have been found to be deficient and other techniques not initially recommended found to be of value. Under this project, CBT will revise and publish a new document that details these thermal data requirements and evaluation procedures.

To date, most investigations of passive solar use have been aimed at low-density, suburban and rural applications. However, most of the Nation's buildings (both residential and commercial) are located in urban settings. These settings may have high potential both for solar access and energy conservation, but current evaluation techniques are largely inadequate for assessing the solar and thermal performance of the large-scale passive solar designs that show greatest promise at reducing energy consumption in such urban surroundings. This project identifies a number of prototypical individual buildings to represent classes of urban construction in representative urban environments (block and street scale) and to study the trade-offs between building energy use and solar availability. In FY81, the selection and documentation of the individual prototypical buildings, urban environments, and methods for analyzing solar availability and building energy use will be completed. Assistance will also be provided to DoE in the planning of future NBS research and in coordinating these research efforts with demonstration projects. 


\section{Commercial Solar Energy Demonstration}

\author{
Robert D. Dikkers \\ (301) 921.3285 \\ Building Economics and Regulatory \\ Technology Division
}

Sponsor: Department of Energy

\section{Monitoring of Radon Concentration in Passive Solar Buildings}

Samuel Silberstein

(301) $921-2758$

Building Thermal Performance Division

Sponsor: Department of Energy
CBT staff members have participated in the preparation of draft standards and performance criteria and have participated in the evaluation of commercial solar system performance. Experience gained from the evaluation of system performance will be fed back into the development of improved criteria. CBT staff will seek comments and suggestions on existing performance criteria from industry, designers, and other members of the building community. In regard to standards development, CBT staff will work with appropriate ANSI, ASME, ASHRAE, and ASTM committees. CBT also will assist DoE in a study of a voluntary laboratory accreditation program.

The National Research Council Canada (NRCC) is completing a thorough review of indoor air quality, with CBT's technical assistance. CBT intends to use the review in advising DoE of areas needing further research. NBS participation with staff of the Lawrence Berkley Laboratory on a national strategy for determining health effects of passive solar energy concluded that a major problem was emission of radon by massive masonry, and radon's decay into carcinogenic radon daughters. Six test structures, identical except for their walls, were constructed at CBT for conducting thermal performance measurements. Here it will be possible to study, in isolation, the effects of thermal mass on radon concentration and the working level. There will be no interference from other sources or complications rising from human occupancy. Such a study has never been done.

Findings and recommendations will be presented to $\mathrm{DoE}$ and various technical and professional societies. The work will result in the identification of research needed to deal with the problem of indoor air quality, especially with respect to passive solar buildings. The measurements in the test houses will demonstrate the possibility of controlled in-situ radon concentration and working-level measurements. The results may be used as a basis for limiting radium content of masonry used in passive solar structures, or requiring a minimum ventilation rate or a maximum radon emanation rate. They can be used to select those passive solar strategies that pose the least health risk to occupants, encouraging popular acceptance of passive solar techniques. 


\section{Technical Support to the Solar Standards Committees}

Robert D. Dikkers

(301) 921-3285

Building Economics and Regulatory Technology Division

Sponsor: Department of Energy

International Cooperation in Solar Energy

Kent Reed

(301) 921-2640

Building Equipment Division

Sponsor: Department of Energy
The primary goal of the National Program for Solar Heating and Cooling of Buildings is "to work with industry in the development and early introduction of economically competitive and environmentally acceptable solar energy systems to help meet national energy requirements." To help achieve this goal, it will be necessary to establish standards, i.e., safety, thermal performance, durability/reliability, for solar heating and cooling equipment. More specifically, standards for solar heating and cooling systems and components are needed to establish acceptable minimum requirements for health and safety as well as acceptable minimum levels of technical performance. Such minimum requirements and levels of technical performance are also desirable for the purposes of consumer acceptance, mortgage insurance, tax credit or incentive programs, and industry commercialization. Under this project, NBS staff members are actively participating in committees which are planning and preparing national consensus standards for solar heating and cooling applications.

CBT has a major role in the preparation of performance criteria and test methods for using solar energy in the United States. DoE has requested that this expertise be used to contribute to the formulation and evaluation of solar collector testing procedures being developed by various countries participating in an International Energy Agency (IEA) Working Group. This project will foster the development of IEA-recommended test procedures by participating in international critiques of U.S. and foreign standards and proposed test procedures and by taking part in round-robin thermal performance and durability tests of various collectors. 



\section{Buslling \\ communsoify Inders \\ Building \\ Community Index}

Buadding

Comnunsoify Inders

Bumding

Communifiy Inders

Buddolng

Communanty Inders

Budiding

Comanusuifty Indexs

Bumfong

Conmanunity Indorex

Busiloling

Comonuminty Index 


\section{BUILDING COMMUNITY INDEX}

The following listing presents the CBT projects organized by their interest to segments of the building community. The projects are listed under the appropriate building community groups as noted below.

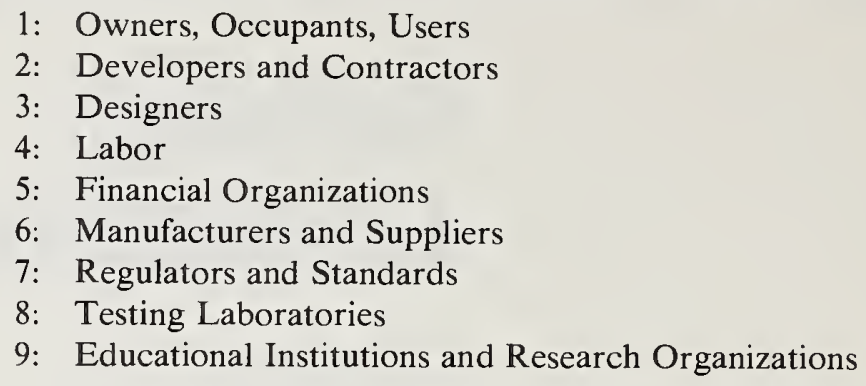

\section{BUILDING ECONOMICS}

Economic Methods for Building Standards, p. 2

Economic Measures of Productivity in the Construction Industry, p. 2

Economic Impact of NBS Electronics Research Effort, p. 2

\section{BUILDING REHABILITATION TECHNOLOGY}

Application of Equivalency Methods to Regulations Related to Health and Sanitation, p. 4

Regulatory Provisions for Existing Buildings, p. 4

Restoration Standards for Porcelain Finishes, p. 4

Monitoring the White House Restoration, p. 5

Quick-Response Studies for HUD, p. 5

Development of Architectural Accessibility Guidelines, p. 5

\section{BUILDING AND COMMUNITY ACOUSTICS}

Building Acoustics Technology, p. 8

Highway Noise Criteria, p. 8

Sound Absorption Measurement, p. 8

Technical Support to the EPA, p. 9

\section{LIGHTING TECHNOLOGY}

Lighting Technology, p. 12

Task Lighting Criteria, p. 12

Measurement of Illumination Sýstems Effectiveness, p.13

Laboratory and Field Illumination Measurements, p. 13

Chromatic Adaptation, p. 13

Visual Acuity Requirements for Nondestructive Testing, p.14

\section{BUILDING SERVICE SYSTEMS PERFORMANCE}

Performance of Water-Conserving Devices, p. 16

User Acceptance of Water Conservation, p. 16

Guidelines for Limited Venting and Single-Stack Drainage Systems, p. 16

Solid Transport in Horizontal Drains, p. 17

Plumbing Vent Systems Network Analysis, p. 17

Service Life of Electrical Wire Insulation, p. 18

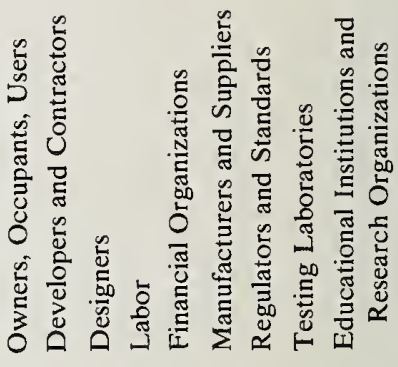

$\begin{array}{lllllll} & X & & X & & X & \\ X & X & X & X & X & X & \\ X & & X & & X & \\ & & & & & \end{array}$

\begin{tabular}{|c|c|c|c|c|}
\hline & $X$ & $X$ & & \\
\hline$X X$ & $X$ & & $X$ & \\
\hline & $X$ & $X$ & X & $X$ \\
\hline & $X$ & $X$ & & $X$ \\
\hline X & $X$ & $X$ & $X$ & $X$ \\
\hline$X \quad X$ & $\mathrm{X} X$ & $X$ & $X$ & \\
\hline
\end{tabular}

\begin{tabular}{|c|c|}
\hline$X \quad X \quad X$ & $X \quad X$ \\
\hline$X X X$ & $X X$ \\
\hline$X \quad X \quad X$ & $X \quad X \quad X$ \\
\hline$X$ & $X X$ \\
\hline
\end{tabular}

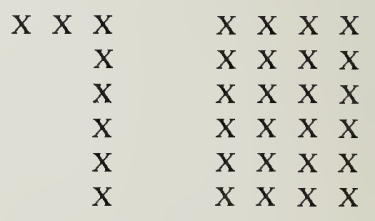

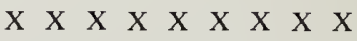

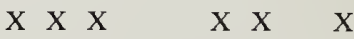

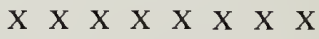

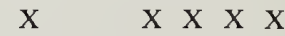

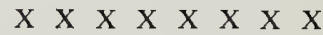

$\begin{array}{lllllllllllllllll}X & X & X & X & X & X & X\end{array}$ 


\section{STRUCTURES AND FOUNDATIONS PERFORMANCE}

Criteria for Structural Loads and Design, p. 20

Snow Loads on Nuclear Power Plant Structures, p. 20

Application of Life-Test Analysis Concepts to Building Components, p. 21

CBT Wind Tunnel: Performance Criteria and Final Design, p. 21

Criteria for Design of Cladding Subjected to Wind Loads, p. 22

Performance of Residential Siding, p. 22

Construction of Housing in Mine-Subsidence Areas, p. 22

Requirements and Format for the Siting of LNG Facilities, p. 23

Foundation and Excavation Standards, p. 23

Geotechnical Measurements of In-Situ Soil Properties, p. 23

Ultimate Limit States for Joints and Fasteners in Light-Frame Construction, p. 24

Reliability-Based Design of Containments and Category I Structures, p. 24

Anchoring Mechanics for Mobile Homes, p. 25

Mobile Home Anchoring in Flood Plains, p. 25

NDE of Building Materials, p. 26

NDE for Concrete Strength, p. 26

Interpretation of Ultrasonic NDE Results, p. 26

Cement Hydration, p. 27

Fly Ash Use in Cement and Concrete Products, p. 27

Organic Coatings, p. 28

Corrosion of Steel in Prestressed Concrete p. 28

Short-Term Evaluation of Steel Coatings, p. 29

Field Adhesion Tester, p. 29

Properties of Single-Ply Roofing Systems, p. 29

Measurements and Standards for Nuclear Waste Management, p. 30

Tri-Services Technical and Scientific Support, p. 30

\section{EARTHQUAKE HAZARD REDUCTION}

Seismic Provisions for Buildings, p. 32

Seismic Limit-States for Structures, p. 32

Romania Earthquake Rehabilitation, p. 33

Computer-Controlled Test Facility, p. 33

Cyclic-Loading of Masonry Building Components, p. 33

Cyclic-Strain Approach to the Determination of Liquefaction Potential of

Level Sandy Sites, p. 34

Improving the Standard Penetration Test as a Measure of the Liquefaction Potential of Sands, p. 34

\section{BUILDING SAFETY}

Construction Load Evaluation, p. 36

Excavation Safety, p. 36

Effectiveness Evaluation of Symbol Use, p. 36

Effectiveness of Safety Symbols in the Workplace, p. 37

Building Circulation Evaluation System: Phase I, p. 37

Modeling Occupant Circulation Systems, p. 38

The Use of Hazard Pictorials/Symbols in Mines, p. 38

Technical Support for Correctional Facilities Design Standards, p. 39

\section{ENERGY CONSERVATION IN BUILDINGS}

Building Energy Performance Criteria, p. 42

Integrated Energy Systems, p. 42

Energy Analysis Procedures, p. 42

Energy Analysis of the Norris Cotton Building, p. 43

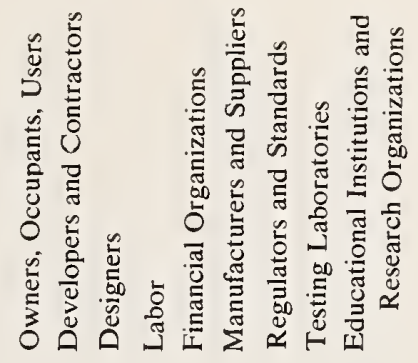

\begin{tabular}{|c|c|c|c|c|c|c|}
\hline & & $\mathrm{X}$ & & $X \quad X$ & $\begin{array}{ll}X \\
X\end{array}$ & $X$ \\
\hline & $X$ & $\mathrm{X}$ & & $\mathrm{X} X$ & & X \\
\hline & $X$ & & & $X \quad X$ & & \\
\hline & & X & & X & & \\
\hline & & $X$ & & $X \quad X$ & $\begin{aligned} x \\
X\end{aligned}$ & \\
\hline$X$ & $X$ & $X \quad X$ & $X$ & $X \quad X$ & $x \quad X$ & \\
\hline$X$ & $X$ & $X \quad X$ & $X$ & $X X$ & & \\
\hline & & $X \quad X$ & & & $\mathrm{~K} X$ & \\
\hline & $X$ & $X X$ & & $X X$ & $\begin{array}{ll}x \\
X\end{array}$ & \\
\hline & $x$ & & & $X \quad X$ & $X$ & \\
\hline & & $\mathrm{X}$ & & $X X$ & $x \quad X$ & \\
\hline & & $X$ & & $X X$ & & \\
\hline$X$ & $X$ & $X$ & & $X X$ & K X & \\
\hline$X$ & $X$ & $X$ & & $X X$ & $\mathrm{~K} X$ & \\
\hline & $X$ & $X$ & & $X X$ & $K X$ & \\
\hline & $X$ & $X$ & & $\mathrm{X} X$ & $K \mathrm{X}$ & \\
\hline & $X$ & $X$ & & $X \quad X$ & $\begin{array}{ll}K \\
X\end{array}$ & $y$ \\
\hline & $X$ & $\mathrm{X}$ & & $X \quad x$ & $x \quad X$ & \\
\hline & $X$ & $X$ & & $X \quad X$ & $x$ & \\
\hline & $\mathrm{X}$ & $X$ & & $X X$ & $5 X$ & \\
\hline & $X$ & $\mathrm{X}$ & & $X \quad X$ & K X & \\
\hline & & $X$ & & $X X$ & $x \mathrm{X}$ & \\
\hline & $X$ & $X$ & & $X \quad X$ & $K X$ & \\
\hline$X$ & $X$ & $X \quad X$ & & $X \quad X$ & $x$ & \\
\hline & & $X X$ & & $X \quad X$ & 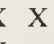 & \\
\hline & & $X$ & & $X \quad X$ & & \\
\hline
\end{tabular}

$\begin{array}{llllll}\mathrm{X} & \mathrm{X} & \mathrm{X} & & \mathrm{X} \\ \mathrm{X} & \mathrm{X} & \mathrm{X} & \mathrm{X} & \mathrm{X} \\ \mathrm{X} & \mathrm{X} & \mathrm{X} & & \mathrm{X} \\ \mathrm{X} & \mathrm{X} & \mathrm{X} & \mathrm{X} & \mathrm{X} \\ \mathrm{X} & \mathrm{X} & \mathrm{X} & \mathrm{X} & \mathrm{X} \\ \mathrm{X} & \mathrm{X} & \mathrm{X} & \mathrm{X} & \mathrm{X} \\ \mathrm{X} & \mathrm{X} & \mathrm{X} & \mathrm{X} & \mathrm{X} & \mathrm{X}\end{array}$

\begin{tabular}{|c|c|c|c|c|}
\hline & $\mathrm{X} X$ & & $X$ & $\mathrm{X}$ \\
\hline & $x \quad x \quad x$ & & $\mathrm{X}$ & $X$ \\
\hline $\mathrm{X}$ & $x \times x$ & $X$ & $\mathrm{X}$ & X \\
\hline $\mathrm{x}$ & 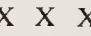 & $X$ & $\mathrm{X}$ & \\
\hline & $X \quad X$ & $\mathrm{X}$ & $\mathrm{X}$ & $X$ \\
\hline & $x \quad x$ & $x$ & $X$ & $X$ \\
\hline & $X X$ & $X$ & $X$ & $X$ \\
\hline & $X X$ & $X$ & $X$ & \\
\hline
\end{tabular}

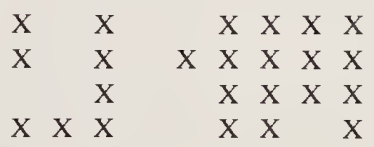


Energy Analysis of Control Strategies, p. 43

Thermostat Test Standard, p. 44

CBT Controls Laboratory, p. 44

EMCS Algorithms, p. 45

EMCS Measured Performance, p. 45

Retrofit Instrumentation Technology/EMCS Sensors, p. 45

Dynamic Performance of HVAC Systems and Controls, p. 46

Laboratory Tests for Thermographic Standards, p. 46

Air Infiltration in Large Buildings, p. 46

Evaluating the Performance of Heat Pumps, p. 47

Heat Pump and Air Conditioner Test Procedures, p. 47

Furnace and Boiler Test Series, p. 48

Underground Heat Distribution Systems, p. 48

Daylighting Prediction, p. 48

Radon Transport in Building Materials. p. 49

\section{BUILDING THERMAL ENVELOPE SYSTEMS AND INSULATING MATERIALS}

Thermal Conductivity Apparatus, p. 52

Thick Insulation Test Series, p. 52

Thermal Insulation Analysis, p. 52

Calibrated Hot Box Construction, p. 52

Calibrated Specimen Round-Robin Tests, p. 53

Multi-Room Thermal Modeling, p. 53

Installation Criteria for Building Retrofit, p. 53

Field Measurements of Building Thermal Mass, p. 53

Guidelines for Controlling Attic Condensation, p. 54

Field Determination of Wire Temperatures, p. 54

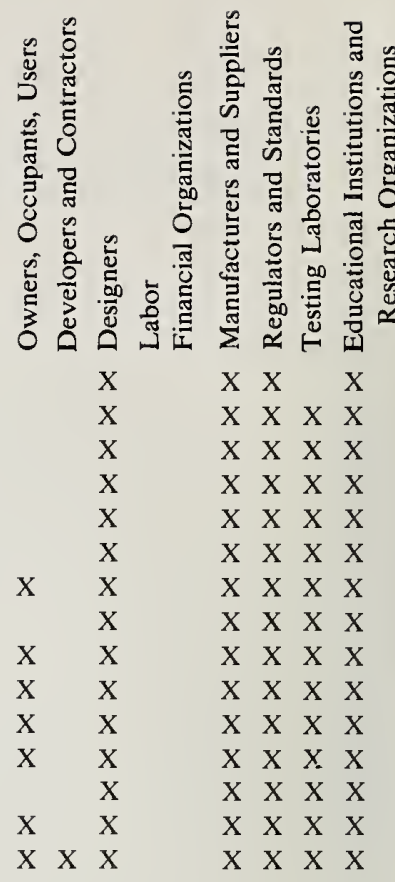

\section{BUILDING SOLAR SYSTEMS TECHNOLOGY}

Collector Durability and Reliability Test Program, p. 56

Standards for Solar Absorptive Coatings, p.56

Standards for Solar Cover Plates, p. 57

Standards for Optical Property Measurements, p. 57

Thermal Test Methods for Solar Collectors, p. 58

Test and Evaluation of Solar Collectors, p. 58

Standards for Nonmetallic Containment Materials, p. 58

Standards for Rubber Hose and Connections, p. 59

Standards for Phase-Change Storage Materials, p. 59

Thermal Energy Storage and Building Codes, p. 60

Development of Solar Regulatory Provisions, p. 60

Cement Hydrates for Energy Storage, p. 60

Solar Energy Program for Housing Systems, p. 61

Kinetics of Glycol-Based Antifreeze Degradation, p.61

Evaluation of IPC Corrosion Test Methodology, p. 62

Solar Hot Water System Test Program, p. 62

Passive Solar Data Requirements, p. 62

Evaluation of Thermal Comfort in Passive Solar Buildings, p. 63

Health and Safety Criteria for Passive Solar Systems, p. 63

Modeling for the Analysis of Thermal Comfort in Passive Solar Buildings, p. 63

Thermal Test Methods for Passive Components, p. 63

Modeling of Passive Solar Buildings, p.64

Standards for Passive Solar Materials, Components, and Systems, p. 64

The Influence of Micro-Changes on the Engineering Properties of Solar Materials, p. 64

Materials Problem Definition: Solar Industrial Process Heat Applications, p. 65

The Industry Impact of Solar Equipment Standards, p. 65

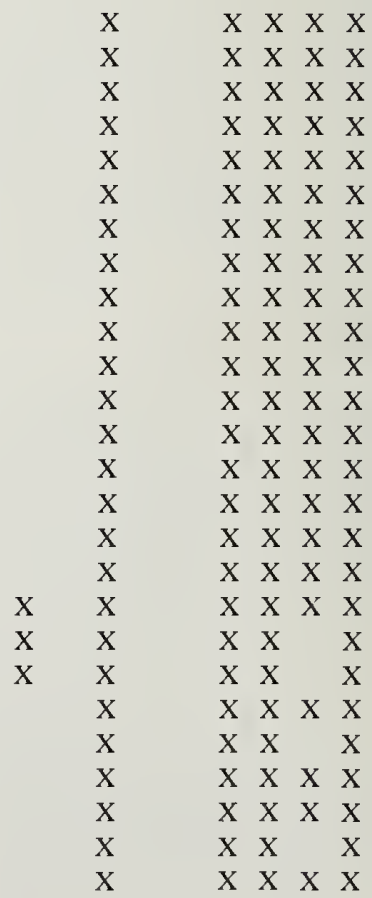


Economic Consultation for the Solar Federal Buildings Program, p. 65 Economics Sessions of the Solar Design Workshops, p. 66

Conservation and Solar Energy: An Integrated Economic Evaluation Framework, p. 66 Comparison of Selected Solar Economic Evaluation Models, p. 66

Cost-Benefit Studies of Solar Federal Building Projects, p. 67

Residential Solar Data Center, p. 67

Solar Systems User Data Base, p. 67

Federal Guide Specifications for Solar Heating and Hot Water Applications, p. 68

Reliability and Maintainability of Solar Heating and Cooling Systems, p. 68

Performance Criteria for Solar Heating and Cooling Systems in Commercial Buildings, p. 68

Technical Assessment of Buildings Being Considered for Solar Retrofit, p. 69

Thermal Performance Data Requirements and Evaluation Procedures, p. 69

Solar Utilization in Cities and Towns, p. 69

Commercial Solar Energy Demonstration, p. 70

Monitoring of Radon Concentration in Passive Solar Buildings, p. 70

Technical Support to the Solar Standards Committee, p. 71

International Cooperation in Solar Energy, p. 71

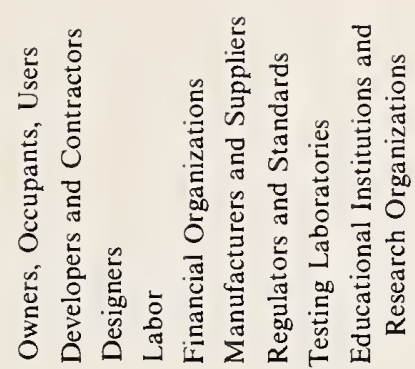

$X \quad X \quad X \quad X$

$\begin{array}{lllllll} & X & X & X\end{array}$

$\begin{array}{lllllll}X & X & X & X\end{array}$

$\mathrm{X} \quad \mathrm{X} \quad \mathrm{X} \quad \mathrm{X}$

$\begin{array}{lllllllll}X & X & X & X\end{array}$

$\begin{array}{llllllll}X & X & X & X & X\end{array}$

$\begin{array}{lllllll}X & X & X & X\end{array}$

$\begin{array}{llllllllll}X & X & X & X & X\end{array}$

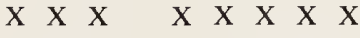

$\begin{array}{llllllllllllllll} & X & X & X & X & X\end{array}$

$\begin{array}{llllllllllllllllll}X & X & X & X & X & X\end{array}$

$\begin{array}{llllllllllllllllllll}X & X & X & X & X\end{array}$

$\begin{array}{lllllllllllll}X & X & X & X & X & X\end{array}$

$\begin{array}{llllllllll}X & X & X & X & X\end{array}$

$\mathrm{X} \quad \mathrm{X} \quad \mathrm{X} \times \mathrm{X} \quad \mathrm{X}$

$X \quad x \quad x$

$\mathrm{X} \quad \mathrm{X} \times \mathrm{X}$ 




U.S. DEPARTMENT OF COMMERCE

National Bureau of Standards

National Engineering Laboratory

Center for Building Technology 